\title{
Quantificação de fatores de crescimento na pele de equinos tratada com plasma rico em plaquetas ${ }^{1}$
}

\author{
Maria V. de Souza ${ }^{2 *}$, José de O. Pinto ${ }^{3}$ Marcela M. da Costa ${ }^{4}$, Eliziária C. dos Santos ${ }^{5}$, \\ Silvana L.R. Garcia ${ }^{6}$ e Leandro L. de Oliveira ${ }^{7}$
}

\begin{abstract}
Souza M.V., Pinto J.O., Costa M.M., Santos E.C., Garcia S.L.R. \& Oliveira L.L. 2014. [Quantification of growth factors in horse skin treated with platelet-rich plasma.] Quantificação de fatores de crescimento na pele de equinos tratada com plasma rico em plaquetas. Pesquisa Veterinária Brasileira 34(6):599-612. Departamento de Veterinária, Universidade Federal de Viçosa, Campus Universitário s/n, Viçosa, MG 36570-000, Brazil. E-mail: msouza@ufv.br

Platelet-rich plasma (PRP) is a product derived from total blood centrifugation, rich in bioactive factors, such as growth factors. Despite largely used in healing processes, there is a controversy whether the therapy is effective in promoting skin healing. The objective of this study was to quantify and compare the concentrations of the factors TGF- $\beta 1$ and PDGF-BB in PRP, blood plasma and skin, at different phases of the healing process of skin treated or not with PRP. Seven healthy crossbred 16 to 17 -year-old geldings $(16.14 \pm 0.63)$ were used. Three quadrangular-shaped lesions $\left(6.25 \mathrm{~cm}^{2}\right)$ were surgically induced into the right and left gluteal regions of all animals. Twelve hours after induction of the wounds, $0.5 \mathrm{~mL}$ of the PRP was administered in each of the four edges of the wound in one of the gluteal regions (Treated group $=\mathrm{TG}$ ) randomly chosen. The contralateral region was used as control (CG). The wounds were submitted to daily cleaning with Milli-Q water, and samples were obtained with a $6 \mathrm{~mm}$ diameter biopsy Punch. Six skin biopsies were obtained, the first carried out immediately after the production of the wound (T0), and the others 1 (T1), 2 (T2), 7 (T3), and 14 (T4) days after the lesion was induced. The sixth biopsy (T5) was obtained after complete healing of the skin, which occurred at about day 37 (36.85 \pm 7.45 , CG; $38.85 \pm 6.46$, TG). EDTA blood samples were also obtained, at all the times mentioned. Quantification of TGF- $\beta 1$ and PDGF-BB growth factors on the skin, PRP, and blood plasma was carried out by the ELISA technique. Data were statistically analyzed by the $t$ test, Pearson correlation and regression, at a significance level of $5 \%$. No difference was found between the groups in the values of the two growth factors measured on the skin, at the different times. Also, no correlation was found between the amount of growth factors present in the skin and plasma. On the other hand, a positive correlation was observed between PRP and skin in the treated group, for the growth factors TGF- $\beta 1$ ( $\mathrm{r}=0.31)$ and PDGF-BB $(\mathrm{r}=0.38)$, as well as between both growth factors present in PRP ( $\mathrm{r}=0.81)$. Considering the growth factor concentrations at T0, the highest skin values $(\mathrm{p}<0.05)$ of TGF- $\beta 1$, in both groups, occurred at T3 and T5. Higher values ( $\mathrm{p}<0.05)$ of PDGF-BB occurred at T4 (TG) and T5 (CG). No plasma changes occurred at the concentration of these factors in relation to $\mathrm{T} 0$, suggest-
\end{abstract}

\footnotetext{
${ }^{1}$ Recebido em 5 de outubro de 2013.

Aceito para publicação em 5 de junho de 2014.

${ }^{2}$ Departamento de Veterinária, Universidade Federal de Viçosa (UFV), Campus Universitário, Avenida Peter Henry Rolfs s/n, Viçosa, MG 36570000, Brasil. *Autor para correspondência: msouza@ufv.br

${ }^{3}$ Doutorando do Departamento de Veterinária, Universidade Federal de Viçosa, Campus Universitário, Avenida Peter Henry Rolfs s/n, Viçosa, MG 36570-000. E-mail: jolip2004@yahoo.com.br

${ }^{4}$ Graduanda do Departamento de Veterinária, Universidade Federal de
}

\footnotetext{
Viçosa, Campus Universitário, Avenida Peter Henry Rolfs s/n, Viçosa, MG 36570-000. Bolsista PIBIC-CNPq. E-mail: marcela.martins@ufv.br

${ }^{5}$ Doutoranda do Departamento de Biologia Geral, UFV, Campus Universitário s/n, Viçosa, MG 36570-000. E-mail: lisacardoso2000@yahoo.com.br

${ }^{6}$ Instituto Viçosense de Ensino e Pesquisa, Faculdade de Viçosa (FDV), Rua Dr. Milton Bandeira 380, Centro, Viçosa, MG 36570-000. E-mail: garciaslr@yahoo.com.br

${ }^{7}$ Departamento de Biologia Geral, UFV, Campus Universitário s/n, Viçosa, MG 36570-000.E-mail: leandro.licursi@ufv.br
} 
ing that PRP does not cause a systemic effect when the procedures adopted in this research are used. Local administration of PRP in the volume studied, $12 \mathrm{~h}$ after surgical induction of cutaneous wound gluteal equine does not cause higher concentrations of the growth factors TGF- $\beta 1$ and PDGF-BB in the plasma and skin during the healing process.

INDEX TERMS: Horses, platelet-rich concentrate, dermatopathy, systemic effect, ELISA.

RESUMO.- 0 plasma rico em plaquetas (PRP) é um produto derivado da centrifugação do sangue total, sendo rico em fatores bioativos, como os de crescimento. Apesar da ampla utilização em processos cicatriciais, há controvérsia sobre a eficácia da terapia na cicatrização cutânea. 0 objetivo desse estudo foi quantificar e comparar a concentração dos fatores TGF- $\beta 1$ e PDGF-BB no PRP, plasma sanguíneo e pele, durante diferentes fases do processo de cicatrização da pele tratada ou não com PRP. Foram utilizados sete equinos machos castrados, mestiços, hígidos, com idade entre $16 \mathrm{e}$ $17(16,14 \pm 0,63)$ anos. Três lesões em formato quadrangu$\operatorname{lar}\left(6,25 \mathrm{~cm}^{2}\right)$ foram produzidas cirurgicamente nas regiões glúteas direita e esquerda de todos os animais. Doze horas após indução das feridas, $0,5 \mathrm{~mL}$ do PRP foi administrado em cada uma das quatro extremidades das feridas de uma das regiões glúteas (Grupo tratado $=$ GT), escolhida aleatoriamente. A região contralateral foi utilizada como controle (GC). As feridas foram submetidas à limpeza diária com água Milli $\mathrm{Q}$ e amostras foram obtidas mediante biópsias realizadas com Punch de $6 \mathrm{~mm}$. Foram obtidas seis biópsias de pele, sendo a primeira realizada logo após a produção da ferida (T0), e as demais com 1 (T1) 2 (T2) 7 (T3) e 14 (T4) dias após a indução da lesão. A sexta biópsia (T5) foi obtida após completo fechamento da pele, que ocorreu aproximadamente aos 37 dias $(36,85 \pm 7,45, \mathrm{GC} ; 38,85 \pm 6,46$, GT). Também foram obtidas amostras de sangue com EDTA em todos os tempos mencionados. A quantificação dos fatores de crescimento TGF- $\beta 1$ e PDGF-BB na pele, PRP e plasma sanguíneo foi realizada pela técnica ELISA. Os dados foram analisados estatisticamente pelo teste $t$, correlação de Pearson e regressão, utilizando nível de significância de 5\%. Não houve diferença entre os grupos, nos valores dos dois fatores de crescimento mensurados na pele, nos diferentes tempos. Também não houve correlação entre a quantidade dos fatores de crescimento presentes na pele e no plasma. Por outro lado, correlação positiva foi observada entre PRP e pele no grupo tratado, para os fatores de crescimento TGF- $\beta 1(r=0,31)$ e PDGF-BB $(r=0,38)$, bem como entre ambos os fatores de crescimento presentes no PRP $(r=0,81)$. Considerando as concentrações dos fatores de crescimento no T0, os maiores valores cutâneos $(\mathrm{p}<0,05)$ do TGF- $\beta 1$, em ambos os grupos, ocorreram nos tempos T3 e T5. Valores mais elevados $(\mathrm{p}<0,05)$ do PDGF-BB ocorreram no T4 (GT) e T5 (GC). No plasma não houve alteração nas concentrações desses fatores em relação ao T0, o que sugere que o PRP não acarreta efeito sistêmico, quando os procedimentos adotados na presente pesquisa são utilizados. A administração local de PRP no volume estudado, 12 $\mathrm{h}$ após indução cirúrgica de ferida cutânea na região glútea de equinos não ocasiona maiores concentrações dos fatores de crescimento TGF- $\beta 1$ e PDGF-BB no plasma sanguíneo e pele, durante o processo de cicatrização.
TERMOS DE INDEXAÇÃO: Cavalos, concentrado rico em plaquetas, dermatopatia, efeito sistêmico, ELISA.

\section{INTRODUÇÃO}

0 plasma rico em plaquetas (PRP) é um produto derivado da centrifugação do sangue total, sendo rico em fatores de crescimento e proteínas estruturais. A concentração das plaquetas depende do sistema utilizado para processamento e dos valores apresentados pelo paciente no momento da coleta do sangue (Boswell et al. 2012). Apesar do seu uso ser considerado uma terapia relativamente antiga, a sua utilização na espécie equina é mais recente, com relatos para tratamento de feridas cutâneas (Carter et al. 2003, De Rossi et al. 2009, Monteiro et al. 2009), tendinopatias (Argüelles et al. 2008, Maia et al. 2009a,b, Bosch et al. 2011, Zandim et al. 2013), desmopatias (Waselau et al. 2008), lesões articulares (Carmona et al. 2007, Yamada et al. 2012), fraturas (Carmona \& López 2011) e, inclusive, laminite (Carmona et al. 2013a). Também já foi utilizado associado a células mesenquimatosas do estroma da medula óssea para tratamento de tendinopatias e desmopatias (Renzi et al. 2013).

Existem vários fatores de crescimento que são liberados a partir dos $\alpha$-grânulos presentes nas plaquetas, sendo alguns dos principais disponíveis no PRP o transformante beta 1 (TGF- $\beta 1$ ), derivado das plaquetas (PDGF), fibroblástico básico (bFGF), epitelial (EGF) e o endotelial vascular (VEGF) (Anitua et al. 2012, Boswell et al. 2012, Renzi et al. 2013). Considera-se que a liberação dos fatores de crescimento pelas plaquetas contidas no PRP pode favorecer a reparação das lesões, e possibilitar o mais rápido retorno à funcionalidade, possivelmente por estimular a neovascularização, que melhora o suprimento sanguíneo e disponibiliza nutrientes necessários à regeneração tecidual.

Considerando a concentração de plaquetas, leucócitos e hemácias em um determinado volume de plasma, existem pelo menos três métodos para a preparação do PRP: aférese (automático), que possibilita a captura de plaquetas pela utilização de filtro descartável; buffy-coat (semi-automático), que permite a separação das plaquetas por centrifugação utilizando kits comerciais (sistemas ACP, GPS II, GPS III, SmartPReP2, etc), e o manual, resultante da centrifugação do sangue total armazenado em tubos contendo anticoagulante. Os custos variam bastante; kits comerciais produzem concentrados de PRP a um valor elevado, e a técnica manual com dupla centrifugação, além de ter menor custo, é de fácil feitura (Maffulli \& del Buono 2012).

0 TGF- $\beta$ é considerado um dos mais importantes fatores de crescimento para o processo de cicatrização cutânea por auxiliar na angiogênese, quimiotaxia e proliferação celular. Adicionalmente, tanto essa proteína como o PDGF estimulam a produção de colágenos, que são os principais compo- 
nentes estruturais do tecido cicatricial maduro, sendo sintetizados por fibroblastos (Czubryt 2012, Yang et al. 2013). As isoformas TGF- $\beta 1$ e PDGF-BB são as mais frequentemente utilizadas para avaliar a qualidade dos componentes ricos em plaquetas pela técnica imunoenzimática ELISA, e os kits humanos disponíveis possuem comprovada reação cruzada com os anticorpos da espécie equina.

Apesar da utilização do PRP como opção terapêutica em diversas enfermidades, não há evidências suficientes que confirmem a sua eficácia no tratamento de feridas cutâneas. Isso se deve, em parte, a região do corpo submetida ao tratamento, a forma de obtenção e composição do PRP (considerando a quantidade de plaquetas e leucócitos), forma de apresentação (líquido; gel), via e frequência de aplicação, volume e momento em que é administrado durante o processo de cicatrização da pele, entre outros aspectos. Adicionalmente, são raras as pesquisas avaliando a resposta à terapia utilizando técnica com alta especificidade e sensibilidade como a ELISA. Portanto, investigação como essa contribui para validação e maior conhecimento da eficácia do plasma rico em plaquetas. Nesse sentido, o objetivo desse estudo foi quantificar e comparar a concentração dos fatores de crescimento TGF- $\beta 1$ e PDGF-BB no PRP, plasma sanguíneo e pele, durante diferentes fases do processo de cicatrização cutânea.

\section{MATERIAL E MÉTODOS}

Essa pesquisa foi aprovada pela Comissão de Ética no Uso Animal (CEUA) da Universidade Federal de Viçosa (DVT/UFV) sob o número de protocolo $96 / 2011$. Os procedimentos foram realizados de acordo com as Normas de Conduta para o Uso de Animais no Ensino, Pesquisa e Extensão do DVT/UFV, o Código de Ética Profissional do Médico Veterinário, os princípios éticos para pesquisa animal, estabelecidos pelo Colégio Brasileiro de Experimentação Animal e a Legislação Brasileira vigente.

Foram selecionados sete equinos mestiços hígidos, machos castrados, com idade entre 16 e $17(16,14 \pm 0,63)$ anos. Apenas animais aparentemente sadios durante exame físico geral e sem afecção dermatológica foram incluídos no experimento.

Os equinos foram colocados em baias individuais de $20 \mathrm{~m}^{2}$, quinze dias antes do início do experimento, onde foram alimentados com feno de tifton 85 e capim elefante picado (Pennisetum purpureum), além de ração farelada própria para equinos. Sal mineral e água foram deixados ad libitum. Esse manejo foi mantido durante toda etapa experimental.

Os animais foram pesados, pulverizados com solução carrapaticida contendo deltametrina e vermifugados com moxidectina $(0,2 \mathrm{mg} / \mathrm{kg} / \mathrm{oral})$, para a eliminação de endo e ectoparasitas. As baias foram limpas duas vezes ao dia para retirada de excretas e reposição da cama.

Três lesões de pele em formato quadrangular foram produzidas nas regiões glúteas direita e esquerda de todos os animais, conforme descrito por Ferreira et al. (2007). Para isso, os locais foram tricotomizados e submetidos à antissepsia local com digluconato clorexidine degermante a $2 \%$ e alcoólico a $0,5 \%$. Os animais foram sedados com xilazina a $2 \%(0,8 \mathrm{mg} / \mathrm{kg} / \mathrm{IV})$, e em seguida foi realizado bloqueio anestésico subcutâneo com cloridrato de lidocaína a $2 \%$, sem vasoconstritor, ao redor do local a ser incisado, utilizando agulha de $21 \mathrm{G}$.

Para produção das feridas cirúrgicas foi utilizado bisturi com lâmina $\mathrm{n}$ ⒉23, e um molde de plástico em formato quadrangular com $2,5 \mathrm{~cm}$ de lado $\left(6,25 \mathrm{~cm}^{2}\right.$ de área), para a remoção dos frag- mentos de pele (epiderme, derme e tecido subcutâneo). As feridas foram identificadas em A, B e C, de cranial para caudal em ambas as garupas. Amostras de pele foram congeladas a $-80^{\circ} \mathrm{C}$ para posterior quantificação de fatores de crescimento. Essa primeira coleta foi considerada como tempo zero (T0). As feridas cicatrizaram por segunda intenção, e durante todo este período foram monitoradas, e após plena cicatrização foi realizada a última biópsia (ferida C). A ferida cirúrgica foi submetida à limpeza diária, com gaze embebida em água Milli Q. Todos os animais receberam soro antitetânico no dia de confecção da lesão de pele. A dor foi reduzida utilizando dose única de tartarato de butorfanol $(0,08 \mathrm{mg} / \mathrm{kg} /$ IV). Não foi utilizado anti-inflamatório nem antibiótico, pois estes poderiam dificultar ou impossibilitar a avaliação do tratamento com PRP.

A obtenção do PRP foi baseada no protocolo descrito por Argüelles et al. (2006). Para isso, após antissepsia local com álcool-iodado, amostras de $144 \mathrm{~mL}$ de sangue foram obtidas com agulhas vacutainer por venopunção da veia jugular externa, em 36 tubos com capacidade para $4,5 \mathrm{~mL}$, contendo o anticoagulante citrato de sódio a 3,2\%. Também foram obtidas amostras de sangue com o anticoagulante EDTA para quantificação de plaquetas e leucócitos totais.

As amostras de sangue foram homogeneizadas e centrifugadas a $120 \mathrm{xg}$ por $10 \mathrm{~min}$. Após essa primeira centrifugação, foi descartado de cada tubo $50 \%$ do plasma sanguíneo presente na superfície, e o restante foi transferido para quatro tubos de polipropileno de $10 \mathrm{~mL}$ sem anticoagulante. 0 botão leucocitário e as hemácias sedimentadas foram descartados. Em seguida, o plasma foi novamente centrifugado a $240 \mathrm{xg}$ por $10 \mathrm{~min}$. Após essa segunda centrifugação o plasma foi dividido em duas frações: o sobrenadante (plasma pobre em plaquetas) e a fração remanescente denominada plasma rico em plaquetas. Um volume de $75 \%$ do plasma obtido de cada tubo foi descartado e o PRP contendo o botão de plaquetas, reservado.

A concentração das plaquetas e leucócitos foi determinada manualmente (método Rees \& Ecker 1923) no PRP e no sangue obtido com EDTA. A quantificação foi realizada em câmara de Neubauer utilizando líquido de Türk para contagem de leucócitos e líquido de Brecher para contagem de plaquetas (Thrall 2007). Imediatamente após obtenção, $2 \mathrm{~mL}$ do PRP foram congelados a $-80^{\circ} \mathrm{C}$ em criotubos até o momento de quantificação dos fatores de crescimento (TGF- $\beta 1$ e PDGF-BB) pela técnica ELISA.

Todos os animais foram submetidos a tratamento local com PRP $12 \mathrm{~h}$ depois de realizada a lesão. Após tricotomia e sedação com xilazina $(0,8 \mathrm{mg} / \mathrm{kg} / \mathrm{IV})$, uma das regiões glúteas, escolhidas ao acaso, foi assepticamente preparada para a administração do PRP (grupo tratado=GT). As feridas da região glútea contralateral (grupo controle=GC) não receberam qualquer infiltração, mas apenas limpeza local com água Milli-Q, conforme realizada também nas feridas tratadas.

O PRP foi preparado imediatamente antes da sua aplicação, que foi realizada utilizando-se agulha 24G. Cada extremidade das três feridas (A, B e C) recebeu 0,5mL do PRP, totalizando $2 \mathrm{~mL}$ por ferida e $6 \mathrm{~mL}$ para cada lado (esquerdo ou direito) da região glútea. Após tratamento, os animais foram mantidos em baias, sendo soltos e monitorados durante todo o experimento.

Amostras de pele foram obtidas para a quantificação dos fatores de crescimento, conforme metodologia descrita por Monteiro et al. (2009) e Deschene et al. (2011). A pele, em toda a sua espessura, foi obtida com a utilização de Punch de $6 \mathrm{~mm}$ de diâmetro, auxiliada com bisturi, um (T1) e dois (T2) dias após realização da lesão, assim como sete (T3) e 14 (T4) dias do procedimento cirúrgico. Adicionalmente, uma nova coleta foi realizada ao término do fechamento da ferida C (T5). 
Para a realização das biópsias, os animais foram sedados com xilazina a $2 \%(0,8 \mathrm{mg} / \mathrm{kg} / \mathrm{IV})$ e, em seguida, foi realizado bloqueio anestésico subcutâneo com cloridrato de lidocaína a 2\% sem vasoconstritor, ao redor do local a ser biopsiado, utilizando agulha de 21G. Os dois primeiros tempos de biópsia realizadas nas feridas A e B corresponderam a primeira e segunda fases de cicatrização da ferida, onde predomina a hemostasia e a resposta inflamatória, enquanto as últimas três coletas se referem as fases de migração e proliferação, assim como de contração e remodelação (última coleta), quando ocorre a angiogênese, fibroplasia e epitelização. A definição dessas fases foi baseada na descrição de Schultz et al. (2011).

Com exceção da última coleta que foi realizada no centro da área cicatrizada, as amostras foram retiradas da periferia da lesão, abrangendo tanto pele íntegra como lesionada, incluindo migração ou reepitelização, e tecido de granulação, de acordo com o tempo de coleta. Foram obtidas duas amostras de pele em cada tempo (T1, T2, T3, T4 e T5), sendo uma para o TGF- $\beta 1$, e outra para o PDGF-BB. Após obtenção dos fragmentos, o excesso de sangue foi retirado de forma asséptica com $\mathrm{NaCl}$ a $0,9 \%$. Na sequência as amostras foram colocadas em criotubos e, em seguida, imersas em nitrogênio líquido a $-196^{\circ} \mathrm{C}$ por alguns segundos, e imediatamente estocadas em freezer a $-80^{\circ} \mathrm{C}$. Posteriormente, os fragmentos de pele foram liofilizados, pesados e voltaram a ser armazenadas a $-80^{\circ} \mathrm{C}$ até realização da análise. Conforme mencionado anteriormente, as feridas não tratadas também foram submetidas à biópsia exatamente no mesmo dia das infiltradas com PRP.

No plasma sanguíneo, obtido mediante centrifugação do sangue total com EDTA antes do início do experimento, assim como nos mesmos dias em que as biópsias foram realizadas, também foram quantificados os fatores de crescimentos. Após obtenção, o plasma foi transferido para eppendorfs e armazenado a $-80^{\circ} \mathrm{C}$ até análise. Para a quantificação dos fatores de crescimento no PRP e plasma sanguíneo, as amostras foram descongeladas em temperatura ambiente, e na sequência o TGF- $\beta 1$ (Quantikine TGF- $\beta 1$ Imunoassay, DB100B, R\&D Systems, LGC Scientific Suplly, Miami, FL, USA) e PDGF-BB (Quantikine PDGF-BB Imunoassay, DBB00, R\&D Systems, LGC Scientific Suplly, Miami, FL, USA) foram quantificados utilizando kits humanos que comprovadamente possuem reação cruzada com anticorpos equinos (Theoret et al. 2001, Sutter et al. 2004, McCarrel \& Fortier 2009, Monteiro et al. 2009, Textor et al. 2011). As concentrações foram determinadas em duplicata, seguindo as instruções do fabricante.

Para a quantificação dos fatores de crescimento, as amostras de PRP foram diluídas na proporção 1:24 e 1:48 para PDGF-BB e TGF- $\beta 1$, respectivamente. No plasma sanguíneo essa diluição foi respectivamente de 1:20 e 1:40. Conforme recomendação do fabricante, todas as amostras utilizadas para quantificação do TGF- $\beta 1$ foram ativadas no dia do procedimento de análise, utilizando $\mathrm{HCl} 12 \mathrm{~N}, \mathrm{NaOH} 10 \mathrm{~N}$ e HEPES, na quantidade recomendada pelo fabricante do kit.

Para extração da proteína as amostras de pele foram descongeladas à temperatura ambiente e colocadas a $-4^{\circ} \mathrm{C}$ durante $12 \mathrm{~h}$ em eppendorfs contendo $1 \mathrm{~mL}$ do reagente (M-Per Mammalian Protein Extration Reagent, CMS Intrumentos Analíticos Ltda, Cosmópolis, SP). Após esse período, as amostras foram transferidas para eppendorfs e, na sequência, centrifugadas a $7.000 \mathrm{xg}$ por 10 min. 0 sobrenadante foi coletado e transferido para eppendorfs, para posterior quantificação da proteína total e dos fatores de crescimento.

A dosagem da proteína total foi determinada utilizando o método de BCA, sendo utilizada uma curva padrão com albumina $(2 \mathrm{mg} / \mathrm{mL})$. As amostras foram diluídas com água destilada na proporção 1:50. Em seguida $10 \mu \mathrm{L}$ das amostras e da curva padrão foram colocadas em microplaca, e na sequência foi adicionado
$190 \mu \mathrm{L}$ do BCA misturado com $\mathrm{CuSO}_{4}$. A placa foi incubada em estufa a $37^{\circ} \mathrm{C}$ durante $30 \mathrm{~min}$, sendo a quantificação realizada em espectrofotômetro, com comprimento de onda de absorbância fixado em $562 \mathrm{~nm}$. 0 resultado foi obtido por meio de curva de regressão linear, sendo normalizados para o peso seco do tecido original. A quantificação dos fatores de crescimento na pele seguiram os procedimentos indicados nos kits de ELISA, sendo as amostras diluídas em 1:4 e 1:2 para TGF- $\beta 1$ e PDGF-BB, respectivamente. A leitura foi realizada em espectrofotômetro de microplacas, com comprimento de onda de absorbância fixado em $450 \mathrm{~nm}$. A leitura foi realizada em duplicata.

A análise estatística foi realizada no software StatSoft 12.0, 2013 (www.statsoft.com). 0 teste t para amostras independentes foi utilizado para comparar os grupos controle e tratado em cada tempo (T0, T1, T2, T3, T4 e T5), bem como em cada fase de cicatrização (hemostasia e inflamatória, versus migração e proliferação, juntamente com contração e remodelação). Além disso, foram comparados os diferentes tempos com a situação inicial (T0) em ambos os grupos utilizando o teste t para dados pareados. Análise de regressão foi realizada para todos os fatores de crescimento, com a finalidade de verificar o efeito do tempo (T0, T1, T2, T3, T4 e T5, que correspondeu a 1, 2, 7, 14 e 37 dias, respectivamente) na concentração dos mesmos. Correlação de Pearson, testada pelo teste $t$, foi realizada para avaliar a associação entre a quantidade dos fatores de crescimento nas plaquetas e nos leucócitos com a do PRP, assim como entre PRP, pele e plasma. Também foi avaliada a correlação entre os dois fatores de crescimento no PRP. Todas as análises foram realizadas a 5\% de significância.

\section{RESULTADOS}

O tempo máximo necessário para cicatrização das lesões foi de 47 dias em ambos os grupos, sendo os valores médios de $36,85 \pm 7,45$ dias nas feridas controles, e de $38,85 \pm 6,46$ dias nas tratadas.

No sangue total e PRP os valores de plaquetas variaram de 100.000 a 150.000 plaquetas/ $\mu \mathrm{L}$, e de 320.000 a 390.000 plaquetas $/ \mu \mathrm{L}$, respectivamente. Já os valores médios de leucócitos variaram respectivamente de 5.600 a 10.900 células/ $\mu \mathrm{L}$ e de 50 a 900 células/ $\mu \mathrm{L}$ no sangue total e PRP. O PRP utilizado possuía aproximadamente 2,8x mais plaquetas e $17 x$ menos leucócitos do que o sangue total.

Não houve diferença $(p>0,05)$ entre grupos tratado e controle com respeito à concentração dos fatores de crescimento na pele, em cada tempo (T1, T2, T3, T4 e T5) avaliado. Análise de regressão revelou que a concentração do PDGF-BB foi influenciada pelo tempo, tanto na pele como no plasma, apenas no grupo controle (Fig.1). Na pele sadia (T0), a concentração de TGF- $\beta 1$ e PDGF-BB foi de $0,94 \pm 0,69 \mathrm{pg} / \mathrm{g}$ e $0,11 \pm 0,19 \mathrm{pg} / \mathrm{g}$, respectivamente. A exceção da concentração TGF- $\beta 1$ obtida no primeiro tempo avaliado (T1) no grupo controle após indução da lesão, todas as demais amostragens apresentaram valores desse fator de crescimento significativamente maiores (Quadro 1) do que a obtida na pele integra. No segundo dia após lesão, a concentração do TGF- $\beta 1$ na pele elevou em ambos os grupos (GC: $p=0,0009$; GT: $p=0,002)$. Esse aumento foi importante $(p=0,0004)$ uma semana após indução da ferida (GC: $32,11 \pm 11,80 \mathrm{pg} / \mathrm{g}$; GT: $31,66 \pm 14,64 \mathrm{pg} / \mathrm{g}$ ). Na determinação realizada após duas semanas, os valores de TGF- $\beta 1$ foram abaixo dos obtidos na primeira semana, mas significativamente maiores (GC: $\mathrm{p}=0,004$; GT: $\mathrm{p}=0,0009$ ) do que a quantidade presente na 

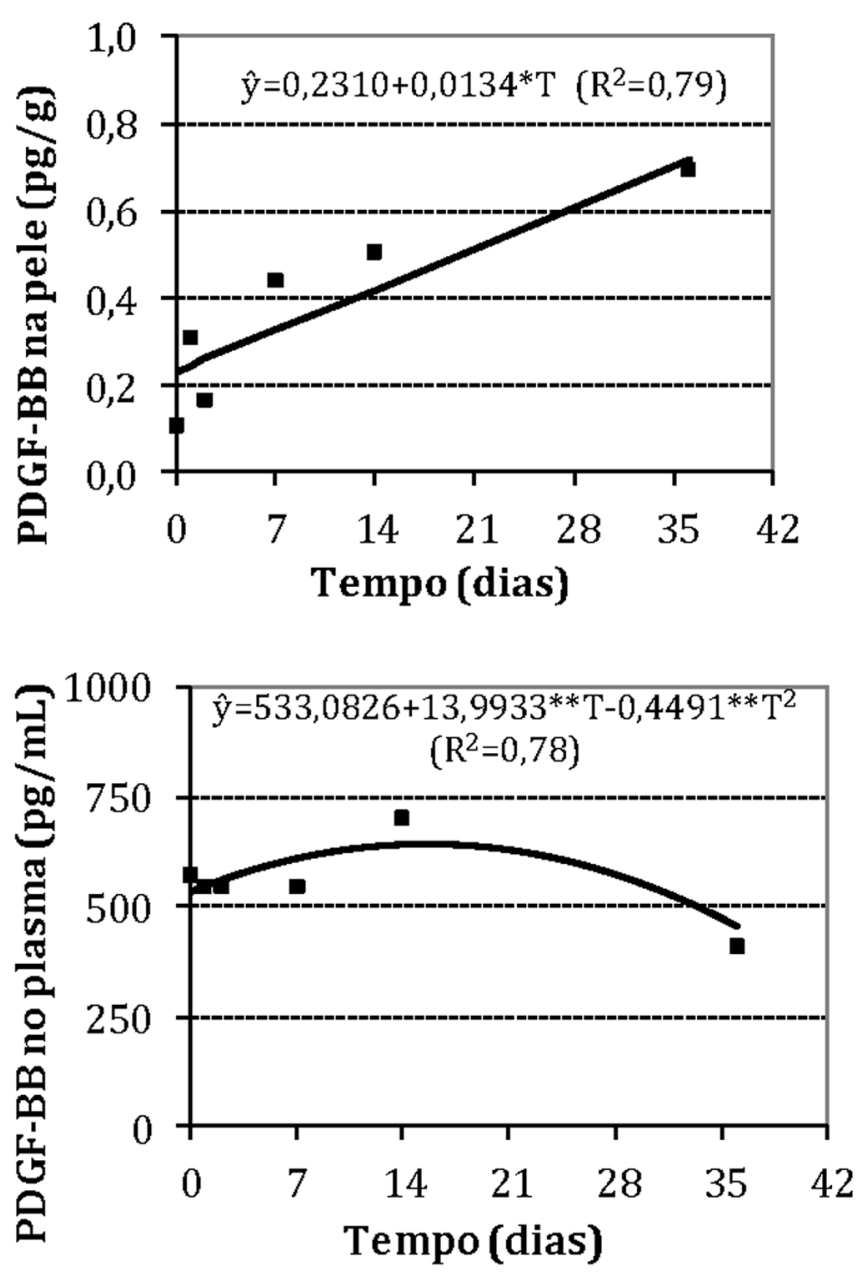

Fig.1. Estimativa do PDGF-BB, em função do tempo, na pele (a) e no plasma sanguíneo (b) dos animais do grupo controle. * $\mathrm{p}<0,05 ;{ }^{* *} \mathrm{p}<0,01$.

Quadro 1. Valores médios e desvios padrão do TGF- $\beta 1$ na pele e plasma sanguíneo dos sete equinos em cada tempo

\begin{tabular}{|c|c|c|c|}
\hline \multirow[t]{2}{*}{ Tempo (dias) } & \multicolumn{2}{|c|}{ TGF- $\beta 1$ na pele $(\mathrm{pg} / \mathrm{g})$} & \multirow{2}{*}{$\begin{array}{c}\text { TGF- } \beta 1 \text { no plasma } \\
(\mathrm{pg} / \mathrm{mL})\end{array}$} \\
\hline & Controle & Tratado & \\
\hline 0 & $0,94 \pm 0,69$ & $0,94 \pm 0,69$ & $2.527,61 \pm 1.229,93$ \\
\hline 1 & $19,15 \pm 24,42 \mathrm{~A}$ & $14,99 \pm 5,35 \mathrm{~A}^{*}$ & $2.440,34$ \\
\hline 2 & $11,65 \pm 4,86 A^{*}$ & $14,24 \pm 6,84 \mathrm{~A}^{*}$ & $2.889,31 \pm 779,88$ \\
\hline 7 & $32,11 \pm 11,80 A^{*}$ & $31,66 \pm 14,64 A^{*}$ & $2.875,01 \pm 867,77$ \\
\hline 14 & $18,23 \pm 10,54 A^{*}$ & $19,17 \pm 8,02 A^{*}$ & $3.068,74 \pm 794,10$ \\
\hline 37 & $36,31 \pm 16,59 A^{*}$ & $24,29 \pm 12,67 \mathrm{~A}^{*}$ & $2.505,27 \pm 995,54$ \\
\hline
\end{tabular}

Fases de hemostasia $15,40 \pm 17,35 \mathrm{Ab} \quad 14,61 \pm 5,91 \mathrm{Ab}$

e inflamatória**

Demais fases*** $\quad 28,88 \pm 14,85$ Aa $25,04 \pm 12,62 \mathrm{Aa}$

Valores médios seguidos por letras maiúsculas diferentes entre colunas, e letras minúsculas entre linhas diferem entre si $(p<0,05)$ pelo teste $t$. * Estatisticamente diferente do tempo 0, a 5\% de probabilidade, pelo teste $\mathrm{t},{ }^{* *}$ Representadas nos dias 1 e $2,{ }^{* * *}$ Representadas nos dias 7 , 14 e 37.

pele íntegra. Na última avaliação realizada, o que ocorreu em média aos 37 dias, foi observado um novo pico de elevação do fator de crescimento (GC: $\mathrm{p}=0,001 ; \mathrm{GT}: \mathrm{p}=0,003$ ).

Os valores do PDGF-BB durante todo o período de cicatrização, incluindo o fechamento da ferida estão apresentados no Quadro 2. Esses valores não foram estatisticamente
Quadro 2. Valores médios e desvios padrão do PDGF-BB na pele e plasma sanguíneo nos sete equinos em cada tempo

\begin{tabular}{cccc}
\hline Tempo (dias) & \multicolumn{2}{c}{ PDGF-BB na pele $(\mathrm{pg} / \mathrm{g})$} & PDGF-BB no plasma \\
\cline { 2 - 3 } & Controle & Tratado & $(\mathrm{pg} / \mathrm{mL})$ \\
\hline 0 & $0,11 \pm 0,19$ & $0,11 \pm 0,19$ & $573,41 \pm 374,52$ \\
1 & $0,31 \pm 0,48 \mathrm{~A}$ & $0,21 \pm 0,34 \mathrm{~A}$ & $389,46 \pm 376,10$ \\
2 & $0,16 \pm 0,26 \mathrm{~A}$ & $0,46 \pm 0,57 \mathrm{~A}$ & $544,17 \pm 187,92$ \\
7 & $0,44 \pm 0,43 \mathrm{~A}$ & $0,53 \pm 0,52 \mathrm{~A}$ & $544,34 \pm 292,17$ \\
14 & $0,50 \pm 0,43 \mathrm{~A}$ & $0,35 \pm 0,32 \mathrm{~A}^{*}$ & $704,26 \pm 193,10$ \\
37 & $0,69 \pm 0,57 \mathrm{~A}^{*}$ & $0,27 \pm 0,42 \mathrm{~A}$ & $412,32 \pm 157,92$ \\
Fases de hemostasia & $0,24 \pm 0,38 \mathrm{Ab}$ & $0,34 \pm 0,47 \mathrm{Aa}$ & \\
e inflamatória** & & & \\
Demais fases*** & $0,54 \pm 0,47 \mathrm{Aa}$ & $0,38 \pm 0,42 \mathrm{Aa}$ & \\
\hline
\end{tabular}

Valores médios seguidos por letras maiúsculas diferentes entre colunas, e letras minúsculas entre linhas diferem entre si $(\mathrm{p}<0,05)$ pelo teste $t$. * Estatisticamente diferente do tempo 0 , a $5 \%$ de probabilidade, pelo teste $t,{ }^{* *}$ Representadas nos dias 1 e 2 , ${ }^{* * *}$ Representadas nos dias 7 , 14 e 37.

diferentes da pele integra até a primeira semana depois de realizada a lesão. No grupo tratado ocorreu elevação $(0,35 \pm 0,32 \mathrm{pg} / \mathrm{g}, \mathrm{p}=0,01)$ da concentração do PDGF-BB com relação ao tempo zero $(0,11 \pm 0,19 \mathrm{pg} / \mathrm{g})$ na amostragem realizada com duas semanas. 0 mesmo foi observado no grupo controle $(0,69 \pm 0,57 \mathrm{pg} / \mathrm{g}, \mathrm{p}=0,04)$ na avaliação efetuada na amostra obtida após fechamento da ferida.

Conforme demonstrado nos Quadros 1 e 2 não houve diferença entre grupos, na quantificação dos fatores de crescimento TGF- $\beta 1$ e PDGF-BB, quando as fases de hemostasia e inflamatória foram comparadas com as demais. Entretanto, a comparação entre fases tanto no grupo tratado como no controle revelou diferença $(\mathrm{p}<0,05)$ para o TGF- $\beta 1$, com menores valores dos fatores de crescimento nas fases de hemostasia e inflamatória. 0 mesmo ocorreu para o PDGF-BB no grupo controle.

Os valores médios de TGF- $\beta 1$ e PDGF-BB no plasma, no momento imediatamente antes do início da indução da lesão (T0) foram de $2.527,61 \pm 1.229,93 \mathrm{pg} / \mathrm{mL}$ e $573,41 \pm 374,52 \mathrm{pg} / \mathrm{mL}$, respectivamente (Quadros 1 e 2). Já no PRP os valores médios foram de $8.693,8 \pm 3.362,58 \mathrm{pg} /$ $\mathrm{mL}$ e $3.964,25 \pm 2.224,19 \mathrm{pg} / \mathrm{mL}$, respectivamente. Os valores mínimos e máximos foram de $4.764,00$ e $13.529,76 \mathrm{pg} /$ $\mathrm{mL}$ e de 1.069 , 2 e $7.470,48 \mathrm{pg} / \mathrm{mL}$ para o TGF- $\beta 1$ e PDGF-BB, respectivamente. Portanto, o PRP apresentou respectivamente, $3 \mathrm{x}$ e $7 \mathrm{x}$ mais TGF- $\beta 1$ e PDGF-BB do que o plasma sanguíneo.

Não houve diferença, ao longo do tempo, na concentração dos dois fatores de crescimento avaliados no plasma sanguíneo. Não foi constatada correlação entre a concentração dos fatores de crescimento no PRP e a contagem de plaquetas ou leucócitos, nem entre as quantidades dos fatores de crescimento na pele e no plasma. Correlação positiva foi observada entre PRP e pele do grupo tratado para os fatores de crescimento TGF- $\beta 1(\mathrm{r}=0,31)$ e PDGF-BB $(r=0,38)$. Também existiu correlação positiva $(r=0,81)$ entre as quantidades de PDGF-BB e TGB- $\beta 1$ no PRP.

\section{DISCUSSÃO}

Aproximadamente 37 dias após indução cirúrgica, as feridas estavam macroscopicamente fechadas. Esse tempo 
médio de cicatrização está próximo $(38,5 \pm 3,9$ dias $)$ ao encontrado por Ferreira et al. (2007) em feridas não tratadas, produzidas da mesma forma e na mesma região. Feridas realizadas na região lateral do pescoço $\left(8 \mathrm{~cm}^{2}\right.$, De Rossi et al. 2009), dorsolateral do metacarpo $\left(6,25 \mathrm{~cm}^{2}\right.$, Monteiro et al. 2009) e superfícies lateral e medial do metacarpo/metatarso $\left(2,5 \mathrm{~cm}^{2}\right.$, Carter et al. 2003), tratadas com PRP em gel, apresentaram períodos máximos de cicatrização entre $72 \mathrm{e}$ 79 dias. Essa variação entre períodos máximos de cicatrização dependem do diâmetro das feridas, mas também da localização, pois lesões cutâneas localizadas no tronco cicatrizam mais rapidamente do que as dos membros (Wilmink \& van Weeren 2005).

Monteiro et al. (2009) constataram que feridas tratadas com PRP, localizadas nos membros, podem apresentar período máximo para fechamento superior (72 dias) ao de feridas não tratadas (62 dias), o que revela que o PRP não tem efeito positivo no tempo máximo para fechamento da ferida; resultados similares aos observados no presente estudo.

Diferentes metodologias podem ser empregadas para a obtenção do PRP. 0 citrato de sódio, anticoagulante utilizado no presente estudo, é considerado como adequado para a preparação desse componente rico em plaquetas, pois se liga aos íons de cálcio formando quelatos, o que impede que ocorra coagulação do plasma (Anitua et al. 2004). Adicionalmente, possui a capacidade de preservar a integridade da membrana das plaquetas (Landesberg et al. 2000), o que é desejável, pois pode evitar a liberação precoce dos $\alpha$-grânulos plaquetários, que possuem os fatores de crescimento.

A lógica para a utilização do PRP reside na inversão da proporção de células vermelhas, as quais são menos úteis no processo de reparação, e na elevação da quantidade de plaquetas, fundamentais no estímulo da reparação tecidual (Marx 2004, Sánchez et al. 2009). 0 método escolhido para quantificar as plaquetas foi o de contagem manual, já que determina de forma individual, e que segundo Vendruscolo et al. (2012) reduz a possibilidade de se subestimar os valores plaquetários. Por outro lado, existe controvérsia sobre a quantidade ideal de plaquetas no PRP. Alguns autores mencionam que deve ser de pelo menos 1 milhão de plaquetas/ $\mu \mathrm{L}$ ou 3 a 6 vezes mais do que a encontrada no sangue total (Marx 2001, Weibrich et al. 2002, Alsousou et al. 2009), que varia de 100.000 a 350.000 plaquetas/ $\mu \mathrm{L}$ (Feldman et al. 2000, Marx 2001). Por outro lado, Anitua et al. (2004) recomendam quantidade mínima de 300.000 plaquetas/ $\mu \mathrm{L}$. No presente estudo essa quantidade foi de 320.000 a 390.000 plaquetas $/ \mu \mathrm{L}$, sendo portanto acima da considerada como apropriada por Anitua et al. (2004), e semelhante à obtida em estudos realizados em equinos hígidos mestiços (Maia et al. 2009b, Vendruscolo et al. 2012, Zandim et al. 2013). Sutter et al. (2004) obtiveram valores médios mais elevados (855.000 plaquetas $/ \mu \mathrm{L})$ mediante utilização de metodologia automática com equipamento que permite a separação (aférese) dos constituintes do sangue total, o que resulta em maiores contagens de plaquetas. Entretanto, na prática clínica, esses aparelhos são pouco utilizados devido ao custo e por não estarem disponíveis em algumas clíni- cas veterinárias, sendo, portanto, mais apropriado o uso de centrífugas convencionais quando se deseja reduzir gastos.

Estudo in vitro realizado por Graziani et al. (2006) demonstrou que preparações de PRP exercem um efeito dose-específico na proliferação de fibroblastos e osteoblastos. Efeitos ótimos foram observados quando a contagem plaquetária foi 2,5x mais alta do que a presente no sangue total. Por outro lado, quantidades mais elevadas $(5,5 \mathrm{x})$ resultaram em efeitos indesejáveis, como a redução da proliferação fibroblástica, e da função dos osteoblastos. De acordo com os autores, diferentes concentrações de plaquetas no PRP podem ocasionar resultados distintos quando estudos in vivo são realizados. Aumento moderado da quantidade de plaquetas no PRP com relação à contagem no sangue total possibilita um ambiente mais adequado para a cicatrização de feridas devido a um melhor equilíbrio entre proliferação e diferenciação celular. Portanto, como a quantidade de plaquetas no PRP preparado no presente estudo foi em média de 2,8x a presente no sangue total, acredita-se que essa quantidade deveria ter sido suficiente para que a terapia resultasse em um fechamento mais rápido da ferida.

A concentração de leucócitos foi mais baixa (50 a 900 células/ $\mu \mathrm{L}$ ) do que a obtida por Vendruscolo et al. (2012) ( $2.460 \pm 763$ células/ $\mu \mathrm{L})$, quando utilizaram força de centrifugação relativa $(g)$ e tempo igual ao usado no presente estudo. É conhecido o efeito positivo dos leucócitos na inflamação, imunidade e sinalização celular (Boswell et al. 2012), assim como na liberação de fatores de crescimento. Entretanto, aos leucócitos também são atribuídos efeitos indesejáveis, já que ao atuar como sinalizadores de células pró-inflamatórias podem provocar catabolismo tecidual (Jacobsen et al. 2008). Além disso, existe relato de que a aplicação de concentrado de plaquetas com leucócitos, para tratamento de paciente com tendinopatia pode aumentar a dor local (Mishra \& Pavelko 2006). Portanto, tanto efeitos positivos como negativos são associados à presença dessas células no PRP. Considerando a relação antagônica entre plaquetas e leucócitos, e os fatores de crescimento e citocinas que são gerados, Wasterlain et al. (2012) sugerem que o PRP ideal para preparações ortopédicas deve conter uma proporção elevada de plaquetas em relação aos leucócitos, de forma a promover uma ação mais anabólica do que catabólica. Por outro lado Boswell et al. (2012) consideram que em feridas infectadas pode ser necessária e eficiente uma maior quantidade de leucócitos.

Tendo em vista a quantidade de plaquetas e leucócitos, os concentrados de plaquetas foram classificados em diferentes categorias. Existe o PRP puro (PRP-P), onde as células brancas são intencionalmente eliminadas, e o PRP com leucócitos (PRP-L) (Ehrenfest et al. 2009). Também existem as plaquetas ricas em fibrina (PRF) (Carmona et al. 2013b) que, diferentemente dos demais concentrados, não necessitam da utilização de anticoagulantes para serem obtidas (Ehresfest et al. 2012). O PRP-L deve possuir entre 5 a $8 x$ mais plaquetas (Ehrenfest et al. 2009, Carmona et al., 2013b) e 3 ou mais vezes maior quantidade de leucócitos (Carmona et al., 2013b) do que o sangue total. Entretanto, não existe consenso de quanto de plaquetas deve existir no PRP para que esse seja considerado como 
puro. Hutchins \& Grabsch (2009) mencionam que deve conter moderada quantidade de plaquetas, que deve ser de 1,5 a $2,5 \mathrm{x}$ a existente no sangue total, enquanto Carmona et al. (2013b) consideram que deve possuir de 1,3 a $4 \mathrm{x}$ a sanguínea. Adicionalmente, esses autores mencionam que esse concentrado pode conter de 0,5 a $2 x$ mais leucócitos do que o sangue. Quando o concentrado rico em plaquetas é ativado por agentes farmacológicos, formando um polímero de fibrina, é conhecido como gel de plaquetas (GP). Portanto, um GP obtido a partir de um PRP-P é denominado de PRG-P, e quando originado de um PRP-L, de PRG-L.

Por conseguinte, ainda existe controvérsia na definição desses concentrados de plaquetas. 0 que se sabe até o momento é que cada metodologia pode produzir um produto diferente, possivelmente com distintos potenciais terapêuticos (Ehrenfest et al. 2009), e com variada quantidade e cinética de liberação dos fatores de crescimentos (Ehrenfest et al. 2009, Mazzucco et al. 2009, Sánchez et al. 2009). Levando em consideração as definições básicas para esses componentes ricos em plaquetas, pode-se dizer que no presente estudo foi utilizado um PRP pobre em leucócitos (PRP-PL), o qual pode resultar, quando comparado com o PRP rico em leucócitos (PRP-RL), em menor resposta inflamatória aguda, menor celularidade e vascularização, conforme relatado por Dragoo et al. (2012) cinco dias após tratamento de tendões de ratos com PRP-PL ou PRP-RL. De acordo com Wasterlain et al. (2012), devido a dificuldade em separar os leucócitos das plaquetas durante a maioria dos protocolos adotados, não é raro se utilizar um PRP-RL, que não é adequado quando se deseja uma menor reação inflamatória.

São conhecidas três isoformas de TGF- $\beta$, potencialmente produzidas pela maioria das células ativadas na reparação de feridas, principalmente pelas plaquetas (Chang et al. 1997). Existem evidências de regulação diferenciada pelas isoformas de TGF- $\beta$ (Falanga et al. 1991, Villiger et al. 1993), sugerindo que os mecanismos de estresse, injúria do tecido ou exposição à citocinas podem induzir a um diferente espectro de expressão dessas isoformas. A isoforma TGF- $\beta 1$ é secretada na forma peptídica latente, e ativada por condições ácidas ou por clivagem proteolítica (Chang et al. 1997; Werner \& Grose 2003), sendo responsável por acelerar o processo de reparação. Com relação ao PDGF, são descritas cinco isoformas (Vercoutte-Edouart et al. 2008), sendo a BB considerada a mais potente (Goodkin \& Pierce 1993). A síntese é favorecida como resposta à baixa tensão de oxigênio, trombina e por estímulos resultantes de outros fatores de crescimento (Carrasco et al. 2009). Tanto a quantidade de plaquetas como de leucócitos influencia na quantidade desses fatores de crescimentos. 0 protocolo utilizado para obtenção do PRP foi eficiente em concentrar os fatores de crescimento estudados. Essa eficiência foi maior para o PDGF-BB, do que para o TGF- $\beta 1$, já que o aumento desses fatores de crescimento foi de $7 \mathrm{x}$ e $3 \mathrm{x}$, respectivamente. De acordo com Anitua et al. (2005), concentrados de plaquetas não possuem uma grande quantidade de TGF- $\beta 1$, mas apresentam importantes quantidades de outros fatores de crescimento angiogênicos e proliferativos como PDGF e FGF que também são fundamentais no processo de repa- ração da pele. Os resultados obtidos na presente pesquisa corroboram a afirmativa desses autores.

Os valores do TGF- $\beta 1$ no PRP variaram menos $(4.764,00-13.529,76 \mathrm{pg} / \mathrm{mL})$ do que os obtidos por Textor et al. (2011) em seis equinos sadios, que foram de $1.153 \mathrm{a}$ $22.677 \mathrm{pg} / \mathrm{mL}$. Os valores médios desse fator de crescimento $(8.693,8 \pm 3.362,58 \mathrm{pg} / \mathrm{mL})$ foram relativamente altos, sendo semelhantes aos obtidos por Pereira et al. (2013) $(7.634 \pm 1,218 \mathrm{pg} / \mathrm{mL})$ quando o mesmo protocolo de obtenção foi utilizado, ou seja, duas centrifugações, sendo a primeira com $120 \mathrm{xg} / 10 \mathrm{~min}$, e a segunda com $240 \mathrm{xg} / 10$ min. Adicionalmente, foram bem mais elevados tanto no PRP como no plasma $(2.717,71 \pm 900,61 \mathrm{pg} / \mathrm{mL})$ do que os obtidos por Giraldo et al. (2013) que utilizaram a mesma técnica (ELISA) e os mesmos kits (R\&D Systems) para quantificar esse fator de crescimento no PRP em gel (PRG-P) ativado farmacologicamente com gluconato de cálcio a $10 \%$, em equinos das raças crioula argentina e colombiana $(2.264,0 \pm 1.196,0 \mathrm{pg} / \mathrm{mL}$ no PRP; $1.012,0 \pm 426,0 \mathrm{pg} /$ $\mathrm{mL}$ no plasma), com idade acima de 10.1 anos. 0 mesmo ocorreu com o fator de crescimento PDGF-BB quantificado no presente estudo, cujos valores médios foram de $3.964,25 \pm 2.224,19 \mathrm{pg} / \mathrm{mL}$ e de $527,99 \pm 263,62 \mathrm{pg} / \mathrm{mL}$, para o PRP e plasma, respectivamente. Já os valores médios obtidos por Giraldo et al. (2013) foram de 1.208,0 $\pm 624,3 \mathrm{pg} /$ $\mathrm{mL}$ e $59,3 \pm 131,7 \mathrm{pg} / \mathrm{mL}$, para o PDGF-BB no PRG-P e plasma, respectivamente. Esses autores também realizaram dupla centrifugação, mas por um menor período de tempo (120xg/5 min e $240 \mathrm{xg} / 5 \mathrm{~min}$ ).

Os maiores valores desses fatores de crescimento obtidos no presente estudo, sem que o PRP fosse ativado por agentes farmacológicos, corrobora os achados de Zandim et al. (2012), que demonstraram em estudo ultraestrutural do PRP de equinos que embora a ativação de plaquetas por agentes farmacológicos seja importante, o PRP não ativado por essas substâncias também apresenta adequada porcentagem de plaquetas em estado ativado. Além disso, sabe-se que o estresse mecânico causado pela centrifugação durante o preparo do PRP também pode ativar algumas plaquetas (Gonshor 2002, Landi \& Marques Júnior 2003). Nesse sentido, várias pesquisas realizadas em equinos (Smith et al. 2006, Schnabel et al. 2007, McCarrel \& Fortier 2009, Bosch et al. 2011, Zandim et al. 2013) vem utilizando o PRP sem prévia adição desses agentes ativadores. Portanto, os resultados obtidos no presente estudo corroboram a afirmativa de McCarrel \& Fortier (2009), de que não é necessário o uso de ativadores para liberação dos fatores de crescimento no PRP, o que é reforçado pela correlação positiva observada entre a concentração do TGF- $\beta 1$ e PDGF-BB no PRP e na pele. Essa correlação era esperada, particularmente porque o fator de crescimento derivado das plaquetas induz os macrófagos a produzirem o transformante beta, conforme mencionado por Barrientos et al. (2008).

A metodologia adotada para a preparação do PRP foi baseada na descrita por Argüelles et al. (2006), sendo as concentrações de plaquetas e leucócitos maiores e menores, respectivamente, do que as obtidas por esses autores em concentrado de plaquetas. Por outro lado, esses pesquisadores obtiveram valores médios de TGF- $\beta 1$ superiores 
(10.500pg/mL), embora os valores mínimos e máximos tenham sido bem mais variados (1.900 a $17.100 \mathrm{pg} / \mathrm{mL})$ do que os do presente estudo (4.764,00 a $13.529,76 \mathrm{pg} / \mathrm{mL}$ ). Esses autores incluíram na pesquisa 26 equinos (machos e fêmeas) clinicamente sadios, com idades muito variadas (3 a 12 anos; 6.9 \pm 2.3 ). Embora Textor et al. (2011) não observaram diferença na quantidade de TGF- $\beta 1(p=0,391)$ e PDGF-BB $(p=0,169)$ no PRP de machos e fêmeas, recentemente Giraldo et al. (2013) relataram que existe diferença $(\mathrm{p}<0,001)$ na concentração do PDGF-BB no PRG-P proveniente de fêmeas da raça crioulo colombiana ou equinos jovens (até 5 anos de idade), quando comparados com machos da raça crioulo argentina ou equinos mais velhos (acima de 10,1 anos). Portanto, esses resultados contraditórios entre estudos reforça a necessidade de mais pesquisas in vivo utilizando amostras homogêneas em termos de idade e sexo, conforme realizado no presente estudo.

A variação entre estudos na quantidade de fatores de crescimento presentes no PRP utilizando mesma metodologia de obtenção e técnica para quantificação, também pode estar relacionada com os vários constituintes do PRP, pois além das plaquetas, outras células possuem a capacidade de liberar fatores de crescimento (Weibrich et al. 2003). Adicionalmente, embora a presente pesquisa não tenha revelado correlação, há relato de associação entre a presença de leucócitos e de TGF- $\beta 1$ no PRP, onde valores mais elevados das células brancas resultariam em maiores concentrações do fator de crescimento (Pereira et al. 2013). Conforme mencionado previamente, esse estudo utilizou um PRP-PL, o que pode, portanto, ter resultado em menor concentração do TGF- $\beta 1$.

A pele íntegra da região da garupa dos equinos mestiços do presente estudo apresentou valores médios muito mais baixos de TGF- $\beta 1(0,94 \pm 0,69 \mathrm{pg} / \mathrm{g})$ do que os relatados por Theoret et al. (2001) na pele sadia dos membros torácicos (MTs) e região torácica (RT) de quatro equinos mestiços com idade entre 2 e 4 anos, que foram respectivamente de $980 \pm 396 \mathrm{pg} / \mathrm{g}$ (MTs) e $1.430 \pm 336,0 \mathrm{pg} / \mathrm{g}(\mathrm{RT})$. Esses valores tão diferentes podem estar relacionados com a idade dos animais. Giraldo et al. (2013) compararam a concentração do TGF- $\beta 1$ no PRG-P de equinos com idade até 5 anos, com animais com mais de 10,1 anos, e observaram valores mais altos nos equinos mais jovens $(3.284,0 \pm 2.176,0 \mathrm{pg} / \mathrm{mL}$ ), comparado com os mais velhos $(2.264 .0 \pm 1.196 .0 \mathrm{pg} / \mathrm{mL})$. Adicionalmente, animais com idade entre 5,1 e 10 anos apresentaram valores bem mais próximos $(2.366,0 \pm 1.044,0 \mathrm{pg} /$ $\mathrm{mL}$ ) aos dos equinos mais velhos. Os animais do estudo de Theoret et al. (2001) foram bem mais jovens do que os utilizados no presente estudo. Adicionalmente, a região corporal onde foi quantificado o fator de crescimento também pode ter influenciado, pois já foi comprovado que existe diferença no tempo máximo de cicatrização entre lesões cutâneas localizadas nos membros e no tronco, sendo mais lento nas primeiras (Wilmink \& van Weeren 2005).

De acordo com Theoret et al. (2002a,b), seus estudos foram os primeiros a determinar, de forma temporal, a expressão dos fatores de crescimento TFG- $\beta 1$ e bFGF durante o processo de cicatrização da pele sadia e com tecido de granulação exuberante, na região dos membros torácicos/ tórax e membros torácicos, respectivamente. Diferentemente dos resultados de Theoret et al. (2001), em que o pico de TGF- $\beta 1$ foi observado 24 h após indução cirúrgica de feridas em quatro equinos mestiços, as concentrações de TGF- $\beta 1$ nos animais do presente estudo foram maiores $(p<0,05)$ após uma semana e na avaliação final, quando as feridas nos equinos de ambos os grupos estavam macroscopicamente cicatrizadas. Entretanto, o intervalo de tempo entre as avaliações realizadas por esses autores foi mais próximo (12 e 24h, assim como com 2, 5, 10 e 15 dias), não sendo realizada nenhuma análise após 30 dias de realizada a lesão. Por outro lado, apesar dos valores máximos do fator de crescimento no estudo de Theoret et al. (2001) terem ocorrido com $24 \mathrm{~h}$, permaneceram elevados até o $14^{\circ}$ dia nas feridas localizadas no tórax, e até a cicatrização nas feridas localizadas nos membros. Portanto, existe uma variação muito grande na concentração desse fator de crescimento, de acordo com a localização da lesão cutânea.

Monteiro et al. (2009) avaliaram o efeito do PRP com $2,8 \mathrm{x}$ mais plaquetas do que no soro, em feridas localizadas no aspecto distal dos membros torácicos de seis equinos mestiços, com idade entre 10 e 15 anos, mediante quantificação do TGFß-1 pelo método ELISA. Os autores observaram que a ferida tratada com PRP apresentou 1,6x mais TGF- $\beta 1$ do que a controle após uma semana de realizada a lesão, porém sem diferença estatística entre grupos. No presente estudo, embora tenha ocorrido aumento $(\mathrm{p}<0,005)$ do TGF- $\beta 1$ uma semana após tratamento, o mesmo ocorreu nas feridas não tratadas. Diferentemente do estudo desses autores, a quantidade média desse fator de crescimento nesse tempo de uma semana na ferida não tratada com PRP $(32,11 \pm 11,8 \mathrm{pg} / \mathrm{g})$ foi semelhante ao das feridas tratadas $(31,66 \pm 14,64 \mathrm{pg} / \mathrm{g})$. Esse resultado contraditório se deve, novamente, a localização das feridas. Por outro lado, conforme ocorreu no estudo desses autores, a aplicação tópica do PRP não acelerou macroscopicamente o processo de reparação das feridas.

Da mesma forma que ocorreu para o TGF- $\beta 1$, os valores mínimos e máximos do PDGF-BB no PRP variaram menos $(1.069,2-7.470,48 \mathrm{pg} / \mathrm{mL})$ do que os obtidos por Textor et al. (2011) em seis equinos sadios, que foram de $134 \mathrm{a}$ $7.157 \mathrm{pg} / \mathrm{mL}$. Os valores médios foram mais altos $(\mathrm{p}<0,05)$ do que o do tempo zero, duas semanas depois de realizada a lesão, e na avaliação final, nos grupos tratado e controle, respectivamente. Adicionalmente, em algumas avaliações realizadas, os valores do PDGF-BB foram mais elevados (T1 e T2, GT) do que o obtido em outra amostragem (T3), porém não foram significativamente diferentes da concentração obtida na pele integra. 0 mesmo ocorreu no TGF- $\beta 1$ quantificado em T1 na pele do grupo controle. Essas variações de resultados ocorreram provavelmente em função do desvio padrão que foi elevado nessas amostragens, impedindo que a diferença fosse estatisticamente importante. Por outro lado, esse desvio padrão elevado se deve a variação individual, o que certamente também está relacionado com a contagem de plaquetas e leucócitos totais no PRP.

O PDGF-BB, que pode ser derivado de plaquetas, leucócitos e células endoteliais, participa na quimiotaxia de neutrófilos e macrófagos, e induz os macrófagos (Pierce et al. 
1991) a produzir inclusive TGF- $\beta 1$ (Pierce et al. 1991, Barrientos et al. 2008), conforme mencionado previamente. Também é mitogênico para fibroblastos e miócitos, e tem a capacidade de induzir o fenótipo dos miofibroblastos nos fibroblastos (Clark 1993, Heldin \& Westermark 1999, Barrientos et al. 2008), o que é fundamental para a contração da ferida. Feridas em membros de pôneis cicatrizam mais rapidamente do que em equinos (Wilmink \& van Weeren 2004), o que pode estar relacionado com a maior quantidade desse fator de crescimento. Com base no seu padrão de expressão in vitro Clark (1993) sugere que o PDGF possui dois papeis distintos na cicatrização da pele, sendo um efeito precoce, ao estimular a proliferação dos fibroblastos, e um efeito tardio pela indução dos miofibroblastos. Nesse contexto, a sua elevação em uma fase mais tardia era esperada, e foi considerado como fisiológico, pois no grupo controle ocorreu aumento cutâneo, ao longo do tempo, da concentração desse fator de crescimento.

A ausência de diferença entre grupos tratados e controles pode estar relacionada com o processo de reparação fisiológica das feridas de pele, que se dá, de forma clássica, em quatro fases bem definidas que se sobrepõem, incluindo hemostasia, inflamação, proliferação e, por último, remodelação (Enoch \& Leaper 2007, Young \& McNaught 2011). Schultz et al. (2011) subdivide a terceira fase em migração e proliferação, e a quarta em contração e remodelação. Embora a quantidade de plaquetas presentes no hematoma formado após uma lesão seja de apenas $6 \%$, sendo o restante hemácias (94\%) e leucócitos (1\%) (Marx 2004, Mei-Dan et al. 2010), tanto o TGF- $\beta$ como o PDGF são liberados pelos $\alpha$-grânulos das plaquetas no local onde existe lesão tecidual (Assoian et al. 1983). Theoret et al. (2002a) demonstraram por imunoistoquímica que o TGF- $\beta 1$ é expresso no epitélio da pele sadia de equinos, e que essa expressão é aumentada na pele lesionada, estando associada as células envolvidas no reparo tecidual. Adicionalmente, vários outros fatores podem influenciar na resposta natural do organismo. Além disso, apesar da baixa quantidade de plaquetas no hematoma (condições fisiológicas), o TGF- $\beta 1$ é imediatamente liberado, realizando quimiotaxia para neutrófilos, macrófagos e fibroblastos, que promovem aumento dos níveis desse fator de crescimento em vários tipos celulares, que por sua vez estimulam a migração de células inflamatórias, fibroplasia, síntese de colágenos, angiogênese e a deposição de matriz (Assoian et al. 1983, Pierce et al. 1991). Já o PDGF é encontrado em quantidades elevadas não apenas nas plaquetas conforme mencionado anteriormente, mas também nos leucócitos, células endoteliais vasculares, assim como em outros tipos de células. $\mathrm{Na}$ realidade, em condições naturais, as plaquetas sintetizam e secretam fatores de crescimento durante sua vida útil, que de acordo com Nurden et al. (2008) é de 7 a 10 dias.

Durante a última fase do processo de cicatrização da pele ocorre a ação de miofibroblastos, que são células contráteis originadas da diferenciação de fibroblastos, e que se encontram posicionadas paralelamente no tecido de granulação recém-formado, que parte da periferia da ferida em direção central. Foi demonstrado que a concentração de TGF- $\beta$ é mais alta $(p<0,05)$ em lesões cutâneas de pôneis do que de equinos (Wilmink \& van Weeren, 2004), o que acarreta maior resposta inflamatória, e maior contração da ferida (van den Boom et al. 2002), já que esse fator de crescimento estimula a diferenciação dos fibroblastos em miofibroblastos (Desmoulière et al. 1993), que se ligam ao colágeno fazendo com que haja maior contração, e estímulo à ativação dos fatores de crescimento, tanto do próprio TGF- $\beta$, como do PDGF (Chamberlain et al. 2011).

Apesar da importância do TFG- $\beta 1$ em diferentes fases do processo de cicatrização da pele, esse fator de crescimento também está associado com o desenvolvimento de tecido de granulação exuberante devido a sua função pró-fibrótica (Theoret et al. 2001, van den Boom et al. 2002, Theoret \& Wilmink 2013), portanto a sua permanência elevada no final do processo de cicatrização cutânea pode não ser benéfica. Entretanto, ao que parece essa redução na pele é lenta, já que no presente estudo os valores do TGF- $\beta 1$ permaneceram significativamente altos em relação ao tempo zero $(0,94 \pm 0,69 \mathrm{pg} / \mathrm{g})$, tanto no grupo tratado $(24,29 \pm 12,67 \mathrm{pg} / \mathrm{g})$ como controle $(36,31 \pm 16,59 \mathrm{pg} / \mathrm{g})$, porém não houve a formação de tecido de granulação exuberante. Essa formação de tecido está intimamente relacionada com a inflamação crônica da pele, o que perpetua a liberação de mediadores como o TGF- $\beta$, que por sua vez estimula de forma excessiva a fibroplasia, ocasionando a formação do tecido (Theoret \& Wilmink 2013), o que contraditoriamente inibe a contração (Wilmink \& van Weeren 2005). Na realidade, estudos in vitro demonstraram que baseado no modelo de expressão dos genes do TGF- $\beta$, o efeito desse fator de crescimento no processo de cicatrização cutânea é paradoxo. Enquanto o exógeno estimula a reepitelização, migração de queratinócitos e formação de tecido de granulação (Coffey et al. 1988, Hebda 1988), o endógeno tem demonstrado inibir a reepitelização (Werner \& Grose 2003). Esse fato foi relatado em camundongos por Eskild-Jensen et al. (1997), após tratamento de feridas em orelhas desprovidas de pelo, com anticorpos neutralizantes para TGF- $\beta 1$ e TGF- $\beta 2$. De acordo com os autores, os fatores de crescimento endógenos não foram essenciais para a reepitelização e neovascularização cutânea.

Baseado nos resultados dos diversos estudos mencionados e nos dados obtidos na presente pesquisa, pode-se afirmar que a utilização do PRP como forma de tratamento ainda necessita ser melhor estudada. De acordo com Andia et al. (2012), a origem da eficácia do PRP parece ser mais complexa do que se pensa, sendo importante considerar que as plaquetas possuem centenas de proteínas, de forma que, podem existir outras classes de moléculas (como as citocinas e quimiocinas presentes nos $\alpha$-grânulos) envolvidas na reparação dos tecidos que inclusive podem ser mais importantes do que os fatores de crescimento. Por outro lado, é fundamental ressaltar que mais de $95 \%$ dos fatores de crescimento pré-sintetizados são secretados dentro de $1 \mathrm{~h}$ da ativação dos $\alpha$-grânulos (Marx 2004). No presente estudo a demora em aplicar o PRP não pode ser incriminada como a causa da ausência de diferença entre os grupos, já que uma vez obtido e confirmada a quantidade de plaquetas, o PRP foi imediatamente aplicado, conforme recomendado pela literatura científica (Marx 2004, Vavken et 
al. 2006). Embora se considere 8 h como o tempo máximo para a utilização do PRP após sua obtenção, que é quando pode ocorrer perda da sua estabilidade (Marx 2001, 2004) e deficiência na expressão das proteínas secretoras (Pietrzak \& Eppley 2005), segundo Vavken et al. (2006), o PRP não deve ser armazenado.

Diferentemente do que ocorreu na pele, no plasma não houve alteração nas concentrações dos fatores de crescimento com relação ao tempo zero. De acordo com Marx (2001), os fatores de crescimento atuam nos receptores localizados nas membranas das células, ativando a expressão gênica fisiológica, sem qualquer efeito mutagênico direto. Um possível efeito sistêmico/ergogênico da circulação dos fatores de crescimento é uma discussão que vem sendo realizada, mas os resultados são contraditórios. A possibilidade de efeito sistêmico é considerado um aspecto polêmico na utilização dos concentrados em plaquetas, pois a aplicação local poderia resultar em um melhor desempenho de um atleta após administração do PRP em uma estrutura mole, o que poderia configurar como doping. Esse fato foi bastante discutido em 2010, quando ficou proibida a aplicação intramuscular do PRP em humanos, pela Agência Mundial de Anti-Doping nos Estados Unidos das Américas. De acordo com Wasterlain et al. (2012), embora essa proibição tenha sido posteriormente cancelada devido à falta de provas de que o PRP seria ergogênico, muitos dos fatores de crescimento contidos nos componentes ricos em plaquetas permaneceram proibidos nas listas de substâncias consideradas como doping tanto no ano de 2011 como de 2012.

Até o ano de 2012 apenas Banfi et al. (2006) haviam efetivamente encontrado um possível efeito sistêmico decorrente da administração local do PRP. Os autores mediram as concentrações séricas dos fatores de crescimento EGF e VEGF em quatro pacientes humanos portadores de tendinopatia patelar, e em um com tendinose próxima à articulação úmero-rádio-ulnar. A quantificação foi realizada pela técnica ELISA antes e 30 min após administração da terapia, assim como com 3 e $24 \mathrm{~h}$ depois do tratamento. 0 efeito sistêmico foi atribuído pela diminuição significativa na concentração sérica do EGF já após 30 min da aplicação intratendínea do PRP obtido pelo sistema GPS II, ou seja, método semi-automático. Por outro lado, o efeito permaneceu apenas até a avaliação realizada $3 \mathrm{~h}$ após o tratamento. Por outro lado, o mesmo não foi observado para o VEGF, o que foi atribuído a alta variabilidade interindividual. Recentemente Wasterlain et al. (2013) divulgaram resultados de um estudo onde foi pesquisado o efeito sistêmico de várias proteínas, entre elas os fatores de crescimento semelhante à insulina (IGF-1), bFGF, VEGF e PDGF-BB no soro de 25 pacientes humanos submetidos a tratamento intratendíneo com PRP obtido pelo sistema GPS III (método semi-automático). Os fatores de crescimentos foram quantificados pela técnica ELISA antes do tratamento, $15 \mathrm{~min}$ após realização do mesmo, assim como com 3, 24, 48, 72 e 96h. Efeito sistêmico $(p<0,05)$ foi observado para os fatores de crescimento IGF-1 (aumento com 24 e 48h), bFGF (elevação com 72 e 96h), e VEGF (aumento já na avaliação realizada com $3 \mathrm{~h}$, que permaneceu até a avaliação realiza- da com 96h), mas não para o PDGF-BB, fator pesquisado no presente estudo.

Conforme mencionado, ambos estudos encontraram efeitos sistêmicos para alguns fatores de crescimento, mas não para outros, e o momento em que foram expressadas as alterações séricas variou com a proteína estudada. Adicionalmente, o referido efeito foi antagônico, enquanto em um estudo ocorreu redução (Banfi et al. 2006), no outro foi observado aumento (Wasterlain et al. 2013) do fator de crescimento. Portanto, nesses casos, o efeito sistêmico pode ser considerado uma alteração para mais ou para menos na concentração de fatores de crescimento no soro/plasma/ sangue em comparação com valores basais previamente mensurados antes da aplicação local do PRP, de forma a comprovar que o tratamento agiu em todo o organismo e não apenas no sitio de aplicação. Por outro lado, apesar de Schippinger et al. (2011) considerarem uma possível elevação plasmática de IGF-1 como efeito ergogênico, os autores não encontraram alteração na quantidade do fator de crescimento após uma única aplicação intramuscular de PRP em humanos sadios, sendo portanto considerado pelos pesquisadores um tratamento seguro, pelo menos no que refere a um possível efeito ergogênico. A técnica de obtenção do PRP também foi semi-automática (ACP Arthrex ${ }^{\circledR}$ ), sendo o fator de crescimento quantificado no soro pela técnica ELISA antes da aplicação do PRP, assim como após 0,5, 3 e 24h.

É importante ressaltar que tanto Banfi et al. (2006) como Wasterlain et al. (2013) realizaram o estudo com pacientes apresentando lesão tendínea de ocorrência natural, presentes em diferentes locais, com evolução e severidade não padronizadas. Os autores mencionam inclusive como limitação do estudo a falta de grupo controle. Adicionalmente, a quantificação dos fatores de crescimento em ambos os casos foi realizada no soro, que dependendo da proteína é encontrada em maior quantidade do que no plasma, como é o caso do VEGF (Kraus et al. 2004). Um outro aspecto a ser considerado é a forma de obtenção do PRP, que em ambos os estudos foi pelo método semi-automático que, em geral, origina um PRP-L, ou seja, rico em leucócitos (Ehrenfest et al. 2012). Recentemente Hessel et al. (2014) divulgaram resultados de uma pesquisa onde foram comparadas a concentração de plaquetas e dos leucócitos, assim como do TGF- $\beta 1$ e PDGF-BB em concentrados autólogos de plaquetas obtidos pelo método manual e por quatro diferentes sistemas (Angel, ACP, E-PET e GPS III) utilizados como métodos semi-automáticos. 0 estudo revelou importante variação na composição do PRP; os sistemas E-PET e GPS III apresentaram maiores $(\mathrm{p}<0,001)$ valores de plaquetas com relação aos níveis basais, porém também de leucócitos (GPS III, $p<0,001$ ). A exceção do sistema ACP (Arhrex $\left.{ }^{\circledR}\right)$, ocorreu elevação $(p<0,001)$ do PDGF-BB nos métodos semi-automáticos E-PET e GPS III, assim como no método manual. 0 TGF- $\beta 1$ aumentou em todos os produtos avaliados, a exceção do sistema ACP. Valores mais elevados $(p<0,001)$ foram observados com o kit comercial E-PET e pela técnica manual. De acordo com os autores essas discrepâncias de resultados podem influenciar a bioatividade dos componentes ricos em plaquetas e, consequentemente, influenciar na qualidade da regeneração tecidual. 
Apesar dos resultados obtidos por Wasterlain et al. (2013), os próprios autores acreditam que o aumento obtido para o IGF-I não esteja relacionado com a presença desse fator de crescimento no PRP, já que a quantidade sérica foi mais elevada do que no componente rico em plaquetas. Na opinião dos autores, a elevação se deve, provavelmente, à ativação do hGH-IGF-1, que é um dos principais hormônios relacionados com a produção do IGF-1. No estudo desses pesquisadores ocorreu uma importante elevação desse hormônio nas primeiras $24 \mathrm{~h}$, embora não tenha sido significativa. Adicionalmente, os autores comentam que essa dissociação pode ser reforçada pela ausência de elevação $(p>0,05)$ do PDGF-BB no seu estudo, apesar do seu aumento no PRP. Portanto, se os fatores de crescimentos contidos no PRP fossem os únicos responsáveis pelo aumento dos seus níveis circulantes, também seria esperado alteração sistêmica na quantidade do PDGF-BB. Finalmente, merece destaque o comentário dos autores de que o método utilizado para a preparação do PRP e a técnica de ativação podem afetar a magnitude do efeito sistêmico. Na realidade, eles não utilizaram apenas um PRP-L, mas sim um PRP-RL, que pode provocar a liberação não apenas de fatores de crescimentos anabólicos, mas também catabólicos, o que pode resultar em diferenciada elevação sistêmica de fatores de crescimentos anabólicos. Estudo in vitro recentemente publicado por Boswell et al. (2014), com cultura de tendão de equinos tratada com PRP contendo diferentes proporções de leucócitos e plaquetas, revelou que o grupo que recebeu a maior quantidade de plaquetas apresentou redução na expressão do colágeno tipo I. Por outro lado, o tendão tratado com quantidades mais baixas de leucócitos apresentou menor sinalização catabólica. Na opinião desses pesquisadores, os resultados sugerem que o menor efeito catabólico ocasionado pela baixa concentração de células brancas seja, provavelmente, mais importante do que a alta quantidade de plaquetas, cuja finalidade é maximizar o feito anabólico nos tecidos.

0 presente estudo quantificou fatores de crescimento fundamentais para as diferentes fases do processo de cicatrização cutânea, e utilizou kits humanos com comprovada reação cruzada para equinos. Embora as proteínas TGF- $\beta 1$ e PDGF-BB não tenham sido mensuradas nas primeiras três horas após tratamento das feridas, foram quantificadas em momentos (12 e 36h, por exemplo) que poderiam sinalizar um possível efeito sistêmico. Portanto, os resultados obtidos sugerem que o PRP-PL da forma como foi obtido nesse estudo não possui potencial ergogênico quando injetado por via intradérmica, tendo em vista que não ocorreu redução ou aumento significativos nas quantidades desses fatores de crescimento nos tempos 12 e 36h após administração local, assim como com 1, 2 e 5 semanas. Como futura investigação sugere-se a quantificação desses e de outros fatores de crescimentos em diferentes tempos, durante as primeiras $10 \mathrm{~h}$ após aplicação do PRP, com a finalidade de se verificar se resultados semelhantes são obtidos.

Diferentemente do estudo in vitro de McCarrel \& Fortier (2009) não foi observada correlação entre o TGF- $\beta 1$ e a concentração de plaquetas. 0 estudo desses autores foi realizado em culturas de tendão do músculo flexor digital superficial e ligamento suspensório de equinos. Embora a pesquisa tenha demonstrado correlação positiva entre esse fator de crescimento e a concentração de plaquetas nos diferentes concentrados plaquetários avaliados, não ocorreu o mesmo para o PDGF-BB, o que foi atribuído a forma e ao tempo de liberação desse fator de crescimento, baseado em informações descritas por Lee (2000). Segundo esses autores, o TGF- $\beta 1$ é uma proteina liberada na forma inativa com meia-vida biológica de $90 \mathrm{~min}$, sendo rapidamente ativado após liberação, enquanto o PDGF-BB é liberado a partir das plaquetas na forma ativa, e possuem uma meia-vida inferior a $2 \mathrm{~min}$. Independentemente dos resultados, deve-se ter muito cuidado em se extrapolar e comparar dados obtidos in vitro com os in vivo, conforme comentado pelos próprios autores.

O período de avaliação adotado foi satisfatório, pois abrangeu diferentes fases do processo de cicatrização da pele. Portanto, corroborando o mencionado por Baksh et al. (2013), os benefícios do uso de PRP no contexto clínico ainda permanecem obscuros.

\section{CONCLUSÕES}

Os resultados obtidos no presente estudo permitem concluir que o método manual para obtenção do PRP, utilizando duas centrifugações, é eficiente em concentrar o TGF- $\beta 1$ e o PDGF-BB.

Uma única aplicação local de PRP-PL 12h após indução cirúrgica de lesão cutânea na região glútea não aumenta a expressão local de TGF- $\beta 1$ e PDGF-BB, durante diferentes fases do processo de cicatrização. Adicionalmente, não altera a concentração no plasma sanguíneo desses fatores de crescimento 1, 2, 7, 14 e 37 (aproximadamente) dias após administração.

As fases de migração e proliferação, assim como a de contração e remodelação possuem maiores concentrações dos fatores de crescimento TGF- $\beta 1$ e PDGF-BB, quando comparadas com as fases de hemostasia e inflamatória.

Agradecimentos.- Os autores agradecem à CAPES, FAPEMIG (CVZ-APQ00661-11) e ao CNPq pelo suporte financeiro.

\section{REFERÊNCIAS}

Alsousou J., Thompson M., Hulley P., Noble A. \& Willett K. 2009. The biology of platelet-rich plasma and its application in trauma and orthopaedic surgery: a review of the literature. J. Bone Joint Surg. Brit. 91:987996.

Andia I., Sánchez M. \& Maffulli N. 2012. Joint pathology and platelet-rich plasma therapies. Expert Opin. Biol. Ther. 12:7-22.

Anitua E., Alkhraisat M.H. \& Orive G. 2012. Perspectives and challenges in regenerative medicine using plasma rich in growth factors. J. Control. Release 157:29-38.

Anitua E., Andia I., Ardanza B., Nurden P. \& Nurden A.T. 2004. Autologous platelet source of proteins for healing and tissue regeneration. Thromb. Haemost. 91:4-15.

Anitua E., Andia I., Sanchez M., Azofra J., del Mar Zalduendo M., de la Fuente M., Nurden P. \& Nurden A.T. 2005. Autologous preparations rich in growth factors promote proliferation and induce VEGF and HGF production by human tendon cells in culture. J. Orthop. Res. 23:281-286.

Argüelles D., Carmona J.U., Climent F., Muñoz E. \& Prades M. 2008. Autologous platelet concentrates as a treatment for musculoskeletal lesions in 5 horses. Vet. Rec. 162:208-211. 
Argüelles D., Carmona J.U., Pastor J., Iborra A., Vinals L., Martinez P., Bach E. \& Prades M. 2006. Evaluation of single and double centrifugation tube methods for concentrating equine platelets. Res. Vet. Sci. 81:237-245.

Assoian R.K., Komoriya A., Meyers C.A., Miller D.M. \& Sporn M.B. 1983. Transforming growth factor-beta in human platelets. Identification of a major storage site, purification, and characterization. J. Biol. Chem. 258:7155-7160.

Baksh N., Hannon C.P., Murawski C.D., Smyth N.A. \& Kennedy J.G. 2013. Platelet-rich plasma in tendon models: a systematic review of basic science literature. Arthroscopy, 29:596-607.

Banfi G., Corci M.M. \& Volpi P. 2006. Could platelet rich plasma have effects on systemic circulating growth factors and cytokine release in orthopaedic applications? Brit. J. Sports Med. 40:816.

Barrientos S., Stojadinovic O., Golinko M.S., Brem H. \& Tomic-Canic M. 2008. Growth factors and cytokines in wound healing. Wound Repair Regen. 16:585-601.

Bosch G., Moleman M., Barneveld A., van Weeren P.R. \& van Schie H.T.M. 2011. The effect of platelet-rich plasma on the neovascularization of surgically created equine superficial digital flexor tendon lesions. Scand. J. Med. Sci. Sports 21:554-561.

Boswell S.G., Cole B.J., Sundman E.A., Karas V. \& Fortier L.A. 2012. Plateletrich plasma: a milieu of bioactive factors. Arthroscopy 28: 429-439.

Boswell S.G., Schnabel L.V., Mohammed H.O., Sundman E.A., Minas T. \& Fortier L.A. 2014. Increasing platelet concentrations in leukocyte-reduced platelet-rich plasma decrease collagen gene synthesis in tendons. Am. J. Sports Med. 42:42-49.

Carmona J.U., Argüelles D., Climent F. \& Prades M. 2007. Autologous platelet concentrates as a treatment of horses with osteoarthritis: a preliminary pilot clinical study. J. Equine Vet. Sci. 27:167-170.

Carmona J.U. \& López C. 2011. Autologous platelet concentrates as a treatment for shoulder injury in a horse. J. Equine Vet. Sci. 31:506-510.

Carmona J.U., López C. \& Samudio I.J. 2013a. Autologous platelet concentrates as an adjunctive treatment for chronic laminitis in a mare with pituitary pars intermedia dysfunction. J. Equine Vet. Sci. 33:191-195.

Carmona J.U., López C. \& Sandoval J.A. 2013b. Review of the currently available systems to obtain platelet related products to treat equine musculoskeletal injuries. Rec. Pat. Reg. Med. 12:48-159.

Carrasco J., Bonete D. \& Gomar F. 2009. Plasma rico em plaquetas vs. Plasma rico en factores de crecimiento. Rev. Esp. Cir. Osteoart. 46:127-140.

Carter C.A., Jolly D.G., Worden C.E., Hendren D.G. \& Kane C.J.M. 2003. Platelet-rich plasma gel promotes differentiation and regeneration during equine wound healing. Exp. Mol. Pathol. 74:244-255.

Chamberlain C.S., Crowley E.M., Kobayashi H., Eliceri K.W. \& Vanderby R. 2011. Quantification of collagen organization and extracellular matrix factors within the healing ligament. Microsc. Microanal. 17:779-787.

Chang J., Most D., Stelnicki E., Siebert J.W., Longaker M.T., Hui K. \& Lineaweaver W.C. 1997. Gene expression of transforming growth factor beta-1 in rabbit zone II flexor tendon wound healing: evidence for dual mechanisms of repair. Plast. Reconstr. Surg. 100:937-944.

Clark R.A. 1993. Regulation of fibroplasia in cutaneous wound repair. Am. J. Med. Sci. 306:42-48.

Coffey Jr R.J., Bascom C.C., Sipes N.J., Graves-Deal R., Weissman B.E. \& Moses H.L. 1988. Selective inhibition of growth-related gene expression in murine keratinocytes by transforming growth factor. Mol. Cell. Biol. 8:3088-3093.

Czubryt M.P. 2012. Common threads in cardiac fibrosis, infarct scar formation, and wound healing Fibrogenesis Tissue Repair 5:1-11.

De Rossi R., Coelho A.C.A.O., Mello G.S., Frazilio F.O., Leal R.B., Facco G.G. \& Brum K.B. 2009. Effects of platelet-rich plasma gel on skin healing in surgical wound in horse. Acta Cir. Bras. 24:276-281.

Deschene K., Céleste C., Boerboom D. \& Theoret C.L. 2011. Constitutive expression of hypoxia-inducible factor- $1 \alpha$ in keratinocytes during the repair of skin wounds in horses. Wound Repair Regen. 19:250-259.

Desmoulière A., Geinoz A., Gabbiani F. \& Gabbiani G. 1993. Transforming growth factor-beta 1 induces a-smooth muscle actin expression in granu- lation tissue myofibroblasts and in quiescent and growing cultured fibroblasts. J. Cell. Biol. 122:103-111.

Dragoo J.L., Braun H.J., Durham J.L., Ridley B.A., Odegaard J.I., Luong R. \& Arnoczky S.P. 2012. Comparison of the acute inflammatory response of two commercial platelet-rich plasma systems in healthy rabbit tendons. Am. J. Sports Med. 40:1274-1280.

Ehrenfest D.M.D., Bielecki T., Mishra A., Borzini P., Inchingolo F., Sammartino G., Rasmusson L. \& Everts P.A. 2012. In search of a consensus terminology in the field of platelet concentrates for surgical use: platelet-rich plasma (PRP), platelet-rich fibrin (PRF), fibrin gel polymerization and leukocytes. Curr. Pharm. Biotechnol. 13:1131-1137.

Ehrenfest D.M.D., Rasmusson L. \& Albrektsson T. 2009. Classification of platelet concentrates: from pure platelet-rich plasma (P-PRP) to leucocyte- and platelet-rich fibrin (L-PRF). Trends Biotechnol. 27:158-167.

Enoch S. \& Leaper D.J. 2007. Basic science of wound healing. Surg. 26:3137.

Eskild-Jensen A., Koff J., Kjolseth D., Andersen L.H., Christensen T.M., Baandrup U. \& Hjortdal V.E. 1997. Endogenous TGF-beta1 and TGF-beta2 are not essential for epithelialization and neovascularization in the hairless mouse ear wound model. Ann. Chir. Gynaecol. 86:248-254.

Falanga V., Qian S.W., Danielpour D., Katz M.H., Roberts A.B. \& Sporn M.B. 1991. Hypoxia upregulates the synthesis of TGF-beta 1 by human dermal fibroblasts. J. Invest. Dermatol. 97:634-637.

Feldman B.F., Zinkl J.G. \& Jain N.C. 2000. Schalm's Veterinary Hematology. $5^{\text {th }}$ ed. Lippincott Williams and Wilkins, Philadelphia. 1344p.

Ferreira J.C., Souza M.V., Vilória M.I.V., Fonseca E.F., Vianna M.W.S. \& Costa J.C.M. 2007. Efeitos da monofenilbutazona na cicatrização por segunda intenção em equinos. Ceres 54:263-270.

Giraldo C.E., López C., Álvarez M.E., Samudio I.J., Prades M. \& Carmona J.U. 2013. Effects of the breed, sex and age on cellular content and growth factor release from equine pure-platelet rich plasma and pure-platelet rich gel. BMC Vet. Res. 29:1-10.

Gonshor A. 2002. Technique for producing platelet-rich plasma e platelet concentrate: background and process. Int. J. Periodontics Restorative Dent., 22:547-557.

Goodkin D.A. \& Pierce G.F. 1993. Role of platelet-derived growth factor in osteoblast function and bone synthesis. Wound Repair Regen. 1:203212.

Graziani F., Ivanovski S., Cei S., Ducci F., Tonetti M. \& Gabriele M. 2006. The in vitro effect of diferente PRP concentrations on osteoblasts and fibroblasts. Clin. Oral Implants Res. 17:212-219.

Hebda P.A. 1988. Stimulatory effects of transforming growth factor-beta and epidermal growth factor on epidermal cell outgrowth from porcine skin explant cultures. J. Invest. Dermatol. 91:440-445.

Heldin C.H. \& Westermark B. 1999. Mechanism of action and in vivo role of platelet-derived growthfactor. Physiol. Rev. 79:1283-1316.

Hessel L.N., Bosch G., van Weeren P.R. \& Ionita J.C. 2014. Equine autologous platelet concentrates: a comparative study between different available systems. Equine Vet. J. doi: 10.1111/evj.12288. (Em publicação)

Hutchins G.G. \& Grabsch H.I. 2009. Molecular pathology: the future? Surgeon 7:366-377.

Jacobsen L.C., Sorensen O.E., Cowland J.B., Borregaard N. \& TheilgaardMönch K. 2008. The secretory leukocyte protease inhibitor (SLPI) and the secondary granule protein lactoferrin are synthesized in myelocytes, colocalize in subcellular fractions of neutrophils, and are coreleased by activated neutrophils. J. Leukoc. Biol. 83:1155-1164.

Kraus R.M., Stallings H.W., Yeager R.C. \& Gavin T.P. 2004. Circulating plasma VETGF response to exercise in sedentary and endurance-rained men. J. Appl. Physiol, 96:1445-1450.

Landesberg R., Roy M. \& Glickman R.S. 2000. Quantification of growth factor levels using a simplified method of platelet-rich plasma gel preparation. J. Oral Maxillofac. Surg. 58:297-300.

Landi E.P. \& Marques Júnior J.F.C. 2003. Caracterização da ativação plaquetária nos concentrados de plaquetas por citometria de fluxo. Revta Bras. Hematol. Hemoter. 25:39-46. 
Lee S.J. 2000. Cytokine delivery and tissue engineering. Yonsei Med. J. 41:704-719.

Maffulli N. \& del Buono A. 2012. Platelet plasma rich products in musculoskeletal medicine: Any evidence? Surgeon 10:148-150.

Maia L., Souza M.V., Alves G.E.S., Ribeiro Júnior J.I., Oliveira A.C., Zandim B.M. \& Silva Y.F.R.S. 2009a. Plasma rico em plaquetas no tratamento de tendinite induzida em equinos: avaliação ultra-sonográfica. Pesq. Vet. Bras. 29:241-245.

Maia L., Souza M.V., Ribeiro Júnior J.I., Oliveira A.C., Alves G.E.S., Anjos L.B., Silva Y.F.R.S., Zandim B.M. \& Moreira J.D.C.L. 2009b. Platelet-rich plasma in the treatment of induced tendinopathy in horses: histologic evaluation. J. Equine Vet. Sci. 29:618-626.

Marx R.E. 2001. Platelet-rich plasma (PRP): what is PRP and what is not PRP? Implant Dent. 10:225-228.

Marx R.E. 2004. Platelet-rich plasma: evidence to support its use. J. Oral Maxillofac. Surg. 62:489-496.

Mazzucco L., Balbo V., Cattana E., Guaschino R. \& Borzini P. 2009. Not every PRP-gel is born equal. Evaluation of growth factor availability for tissues through four PRP-gel preparations: Fibrinet, RegenPRP-Kit, Plateltex and one manual procedure. Vox Sang. 97:110-118.

McCarrel T. \& Fortier L. 2009. Temporal growth factor release from platelet-rich plasma, trehalose lyophilized platelets, and bone marrow aspirate and their effect on tendon and ligament gene expression. J. Orthop. Res. 27:1033-1042.

Mei-Dan O., Lippi G., Sánchez M., Andia I. \& Maffulli N. 2010. A revolution in soft tissue sports injury management. Phys. Sports Med. 38:127-135.

Mishra A., Pavelko T. 2006. Treatment of chronic elbow tendinosis with buffered platelet-rich plasma. Am. J. Sports Med. 34:1774-1778.

Monteiro S.O., Lepage O.M. \& Theoret C.L. 2009. Effects of platelet-rich plasma on the repair of wounds on the distal aspect of the forelimb in horses. Am. J. Vet. Res. 70:277-282.

Nurden A.T., Nurden P., Sanchez M., Andia I. \& Anitua E. 2008. Platelets and wound healing. Front. Biosci. 13:3532-3548.

Pereira R.C.F., Zacarias G.V.F., Cantarelli M.M.B.C., Silva G.B., Barbosa A.L.T., Brass K.E. \& De La Côrte F.D. 2013. Avaliação de sete protocolos para obtenção de plasma rico em plaquetas na espécie equina. Ciência Rural 43:1122-1127.

Pierce G.F., Mustoe T.A., Altrock B.W., Deuel T.F. \& Thomason A. 1991. Role of platelets-derived growth factoring wound healing. J. Cell Biochem. 45:319-326.

Pietrzak W.S. \& Eppley B.L. 2005. Platelet rich plasma: biology and new technology. J. Craniofac. Surg. 16:1043-1054.

Rees H.M. \& Ecker E.E. 1923. An improved method for counting blood platelets. J. Am. Med. Assoc. 80:621-622.

Renzi S., Riccò S., Dotti S., Sesso L., Grolli S., Cornali M., Carlin S., Patruno M., Cinotti S. \& Ferrari M. 2013. Autologous bone marrow mesenchymal stromal cells for regeneration of injured equine ligaments and tendons: a clinical report. Res. Vet. Sci. 95:272-277.

Sánchez M., Anitua E., Orive G., Iñigo M. \& Andia I. 2009. Platelet-rich therapies in the treatment of orthopaedic sport injuries. Sports Med. 39:345-354

Schnabel L.V., Mohammed H.O., Miller B.J., McDermott W.G., Jacobson M.S., Santangelo K.S. \& Fortier L.A. 2007. Platelet Rich Plasma (PRP) enhances anabolic gene expression patterns in flexor digitorum superficialis tendons. J. Orthop. Res. 25:230-240.

Schippinger G., Oettl K., Frankhauser F., Spirk S., Domej W. \& Hofmann P. 2011. Influence of intramuscular application of autologous conditioned plasma on systemic circulating IGF-1. J. Sports Sci. Med. 10:439444.

Schultz G.S., Davidson J.M., Kirsner R.S., Bornstein P. \& Herman H. 2011. Dynamic reciprocity in the wound microenvironment. Wound Repair Regen. 19:134-148.

Smith J.J., Ross M.W. \& Smith R.K.W. 2006.Anabolic effects of acellular bone marrow, platelet rich plasma, and serum on equine suspensory ligament fibroblasts in vitro. Vet. Comp. Orthop. Traumatol. 19:43-47.
Sutter W.W., Kaneps A.J. \& Bertone A.L. 2004. Comparison of hematologic values and transforming growth factor-beta and insulin-like growth factor concentrations in platelet concentrates obtained by use of buffy coat and apheresis methods from equine blood. Am. J. Vet. Res. 65:924930.

Textor J.A., Norris J.W. \& Tablin F. 2011. Effects of preparation method, shear force and exposure to collagen on release of growth factors from equine platelet-rich plasma. Am. J. Vet. Res. 72:271-278.

Theoret C.L., Barber S.M., Moyana T.N. \& Gordon J.R. 2001. Expression of transforming growth factor $\beta 1, \beta 3$, and basic fibroblast growth factor in full-thickness skin wounds of equine limbs and thorax. Vet. Surg. 30:269-277.

Theoret C.L., Barber S.M. \& Gordon J.R. 2002a. Temporal localization of immunoreactive transforming growth factor $\beta 1$ in normal equine skin and in full-thickness dermal wounds. Vet. Surg. 31:274-280.

Theoret C.L., Barber S.M., Moyana T.N. \& Gordon J.R. 2002b. Preliminary observations on expression of transforming growth factors $\beta 1$ and $\beta 3$ in equine full-thickness skin wounds healing normally or with exuberant granulation tissue. Vet. Surg. 31:226-273.

Theoret C.L. \& Wilmink J.M. 2013. Aberrant wound healing in the horse: naturally occurring conditions reminiscent of those observed in man. Wound Rep. Reg. 21:365-371.

Thrall M.A. 2007. Diagnóstico dos distúrbios hemorrágicos, p.170-187. In: Ibid. (Ed.), Hematologia e Bioquímica Clínica Veterinária. Roca, São Paulo.

van den Boom R., Wilmink J.M., O'Kane S., Wood J. \& Ferguson M.W. 2002. Transforming growth factor-b levels during second intention healing are related to the different course of wound contraction in horses and ponies. Wound Repair Regen. 10:188-194.

Vavken P., Saad F.A. \& Murray M.M. 2006. Age dependence of expression of growth factor receptors in porcine ACL fibroblasts. J. Orthop. Res. 28:1107-1112.

Vendruscolo C.P., Carvalho A.M., Moraes L.F., Maia L., Queiroz D.L, Watanabe M.J., Yamada A.L.M. \& Alves A.L.G. 2012. Avaliação da eficácia de diferentes protocolos de preparo do plasma rico em plaquetas para uso em medicina equina. Pesq. Vet. Bras. 32:106-110.

Vercoutte-Edouart A.S., Dubreucq G., Vanhoecke B., Rigaut C., Renaux F., Dahri-Correia L., Lemoine J., Bracke M., Michalski J.C. \& Correia J. 2008. Enhancement of PDGF-BB mitogenic activity on human dermal fibroblast by biospecific dextran derivatives. Biomaterials 29:22802292.

Villiger P.M., Kusari A.B., Ten Dijke P. \& Lotz M. 1993. IL-1 beta and IL-6 selectively induce transforming growth factor beta isoforms in human articular chondrocytes. J. Immunol. 151:3337-3344.

Waselau M., Sutter W.W., Genovese R.L. \& Bertone A.L. 2008. Intralesional injection of platelet-rich plasma followed by controlled exercise for treatment of midbody suspensory ligament desmitis in Standardbred racehorses. J. Am. Vet. Med. Assoc. 232:1515-1520.

Wasterlain A.S., Braun H.J. \& Dragoo J.L. 2012. Contents and formulations of platelet-rich plasma. Oper. Tech. Orthop. 22:33-42.

Wasterlain A.S., Braun H.J., Harris A.H.S., Kim H-J. \& Dragoo J.L. 2013. The systemic effects of platelet-rich plasma injection. Am. J. Sports Med. 41:186-193.

Weibrich G., Kleis W.K., Hafner G. \& Hitzler W.E. 2002. Growth factor levels in platelet rich plasma and correlations with donor age, sex, and platelet count. J. Craniomaxillofac. Surg. 30:97-102.

Weibrich G., Kleis W.K.G., Hafner G., Hitzler W.E. \& Wagner W. 2003. Comparison of platelet, leukocyte, and growth factor levels in point-of-care platelet-enriched plasma, prepared using a modified curasan kit, with preparations received from a local blood bank. Clin. Oral. Implants. Res. 14:357-362.

Werner W. \& Grose R. 2003. Regulation of wound healing by growth factors and cytokines. Physiol. Rev. 83:835-870.

Wilmink J.M. \& van Weeren R.P. 2004. Differences in wound healing between horses and ponies: Application of research results to the clinical approach of equine wounds. Clin. Tech. Equine Pract. 3:123-133. 
Wilmink J.M. \& van Weeren P.R. 2005. Second-Intention repair in the horse and pony and management of exuberant granulation tissue. Vet. Clin. Equine 21:15-32.

Yamada A.L.M., Carvalho A.M., Oliveira P.G.G., Felisbino S.L., Queiroz D.L., Watanabe M.J., Hussni C.A. \& Alves A.L.G. 2012. Plasma rico em plaquetas no tratamento de lesões condrais articulares induzidas experimentalmente em equinos: avaliação clínica, macroscópica, histológica e histoquímica. Arq. Bras. Med. Vet. Zootec. 64:318-322.

Yang L., Witten T.M. \& Pidaparti R.M.A. 2013. A biomechanical model of wound contraction and scar formation. J. Theor. Biol. 332:228-248.
Young A. \& McNaught C-E. 2011. The physiology of wound healing. Surgery 29:475-479.

Zandim B.M., Souza M.V., Frassy L.M., Vilória M.I.V., Maia L., Fonseca C.C., Valente F.V., Moreira J.C.L. \& Magalhães P.C. 2013. Immunohistochemistry of factor VIII, histology and morphometry in equine tendon treated with platelet-rich plasma. Revta Bras. Med. Vet. 35:169-184.

Zandim B.M., Souza M.V., Magalhães P.C., Benjamin L.A., Maia L., Oliveira A.C., Pinto J.O. \& Ribeiro Júnior J.I. 2012. Platelet activation: ultrastructure and morphometry in platelet-rich plasma of horses. Pesq. Vet. Bras. 32:83-92. 